Article

\title{
On Hirth Ring Couplings: Design Principles Including the Effect of Friction
}

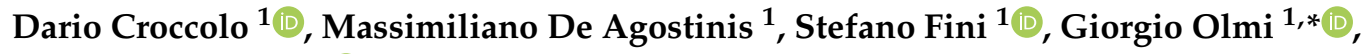 \\ Francesco Robusto ${ }^{1}$ (i) and Nicolò Vincenzi ${ }^{2}$ \\ 1 Department of Industrial Engineering (DIN), University of Bologna, Viale del Risorgimento 2, \\ 40136 Bologna, Italy; dario.croccolo@unibo.it (D.C.); m.deagostinis@unibo.it (M.D.A.); \\ stefano.fini@unibo.it (S.F.); francesco.robusto2@unibo.it (F.R.) \\ 2 GIULIANI, Bucci Automations S.p.A. Division, Via Granarolo 167, 48018 Faenza, Italy; \\ n.vincenzi@bucci-industries.com \\ * Correspondence: giorgio.olmi@unibo.it; Tel.: +39-051-2093-455
}

Received: 21 October 2018; Accepted: 17 November 2018; Published: 21 November 2018

\begin{abstract}
Rings with Hirth couplings are primarily used for the accurate positioning of axial-symmetric components in the machine tool industry and, generally, in mechanical components. It is also possible to use Hirth rings as connection tools. Specific industries with special milling and grinding machines are able to manufacture both tailor made and standard Hirth rings available on stock. Unfortunately, no international standard (for instance ISO, DIN or AGMA) is available for the production and the design of such components. In the best-case scenario, it is possible to find simplified design formulae in the catalogue of the suppliers. The aim of this work is to provide some accurate formulae and computational methods for design to provide better awareness on the limitations and the potential of this type of connection. The work consists of five parts: (i) a review of the base calculation derived mainly from the catalogues of manufacturers; (ii) an improved calculation based on a new analytical method including the friction phenomenon; (iii) an experimentation run for validating the method; (iv) a case study applied to a machine tool; and, (v) a closed form formulation to determine an upper threshold for friction, thus ensuring the Hirth coupling regular performance.
\end{abstract}

Keywords: Hirth rings; connection; serration; frontal teeth; friction; self-centering

\section{Introduction}

Rings with Hirth couplings (Figure 1) are based on the concept of couplings achieved by frontal teeth connections.

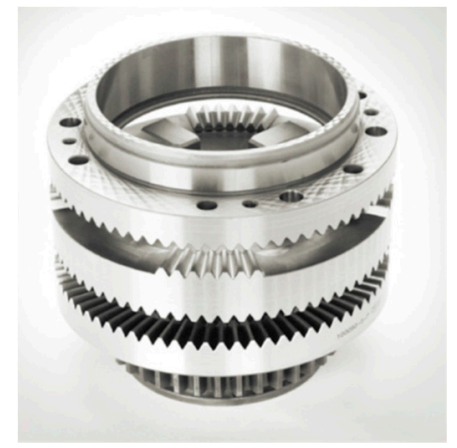

(a)

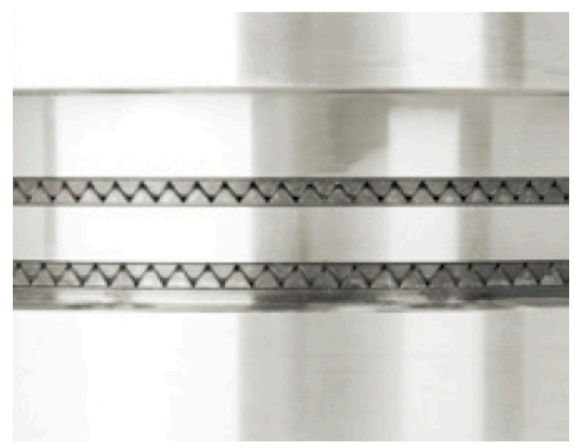

(b)

Figure 1. Example of Hirth rings: (a) disengaged and (b) engaged. 
The concept was invented and patented by a German engineer, Carl Albert Hirth in 1928 [1]. These couplings allow obtaining very high levels of:

accuracy, in terms of relative positioning between the parts connected together;

stiffness of the system, thanks to the steady self-center geometry of the teeth;

power, in terms of torque transmission;

$\bigcirc$ resistance to wear, thanks to a wide support surface of the teeth and the use of special alloyed steels.

For these reasons, Hirth connections are successfully used in many mechanical applications: machine tools, turning tables, transfer units, turbo-chargers, robotics, ship building, and, recently, also in the automotive industry. With regard to the automotive industry, it is possible to highlight the example in Figure 2, dealing with the replacement of the standard splined shaft connection by a frontal teeth connection in the wheel hub. In conventional systems, the drive torque is transferred between the wheel bearing and the axle journal by means of radial splines, which are affected by a certain amount of clearance. Loads that occur in day-to-day driving conditions produce a risk of looseness beyond the normal mounting clearance, resulting in comfort reduction and unpleasant noises and, in some cases, the failure of the bearing. On the contrary, the self-centering axial gear teeth are placed on the axle journal and fixed by the central screw. The connection remains completely clearance-free in the gear teeth during the entire service life. Proceeding this way, it is possible to achieve up to $10 \%$ weight reduction per wheel (resulting in fuel consumption reduction and higher dynamic performance of the vehicle), a simplified assembly operation, a clearance free coupling and, above all, up to $150 \%$ of the torque transmission capability.

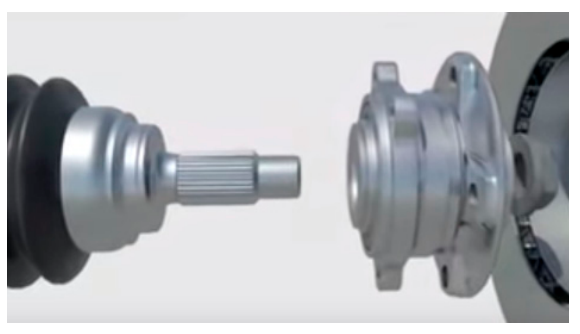

(a)

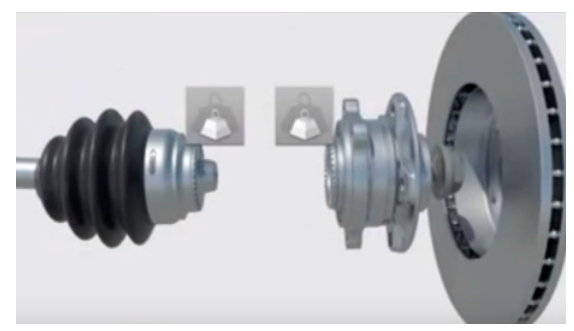

(b)

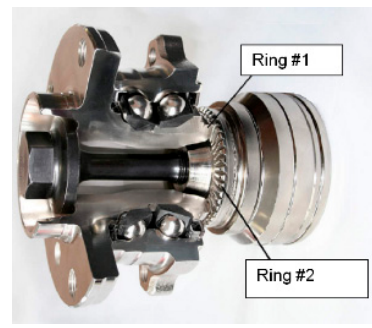

(c)

Figure 2. Example of Hirth connection in automotive: (a) old design with radial teeth and (b,c) new design with frontal teeth.

Hirth couplings, also regarded as curvic couplings, are widely used for torque transmission between mating discs in turbine machinery and are not covered by international standards (for instance ISO, DIN or AGMA). Their application makes it possible to fulfil an accurate centering, as well as an improved reliability and good structural stability. For instance, Reference [2] is focused on the structural and contact analysis of a curvic coupling in a gas turbine. In this study, a numerical model was developed to investigate the stress distribution and the contact evolution at different stages of the turbine service, in particular during preload, warm-up, speed-up, and running. The effects of coupling bolt preload, as well as of torsional load and of environmental temperature were also investigated. Other studies [3-5] have dealt with tooth contact aspects and with applications to turbo-engines in the aerospace industry $[6,7]$.

A further interesting application of Hirth couplings, operating as servo-actuators, is in rotary tables for automatic machines and transfer machine tools [8]. These tables, fixed at predetermined angular positions, must be able to be fully constrained, thus resisting against high tangential forces. At the same time, they must have the capability of transmitting high torque, relying on tooth contact, rather than on friction couplings. Moreover, the Hirth coupling must ensure the accomplishment of strict specifications regarding the precise positioning of the rotating table, from the points of view 
of its angular position and especially its centering with respect to the machine axis, after rotation. The importance of correct alignment is also highlighted in [9,10], dealing with a similar issue.

Most papers in the field of transfer machine tools or of multiple-axis automatic machines are focused on modal or dynamic analyses, such as [11,12]. This research trend is also confirmed by a recent study [13] that deals with the development and validation of a multibody dynamic model of a tool-spindle-bearing system, to be incorporated into a five-axis machine with rotary-tilting spindle heads. Conversely, the topic of the stress peak at the tooth root has not been investigated so far. Moreover, no experimental validation has ever been conducted and published in the scientific literature on numerically computed stress peaks in Hirth couplings. A further unexplored point is the relationship between the stress peak and the actual response of the Hirth connection that may be affected by several factors, such as the force acting on each tooth, the contact area, or the friction affecting the device.

The subject of the present paper is to provide an original analytical model for the Hirth coupling design with regard to the peak stress estimation and to the presence of friction. As remarked above, issues of novelty arise from the lack of similar models in the literature, focused on the actual estimation of the stress maximum value for structural assessment. A further issue of novelty arises from the inclusion of the effect of friction (between the mating teeth or on the bearing surface) in the algorithm. In fact, this is usually disregarded in the standard procedure, but its effect deserves to be considered, as it may be even detrimental for safety and accuracy. The importance of taking friction into account is also emphasized in [2], where the developed curvic coupling finite element model accounts for this item. The present study, as a further evolution, proposes an experimentally validated closed form analytical approach that can be more efficiently applied for industrial design purposes and to properly arrange scheduled maintenance.

\section{Standard Calculation}

Matzke [14] provided some technical data able to give a rough overview of the calculation of Hirth rings. He mainly focused his investigation on the "nominal stress" in the tooth. Based on the nomenclature of Figure 3, the total tangential force $F_{u}(N)$ is applied on the mean radius $R_{m}(m m)$ of the $G$ point (center of gravity) of the tooth section and can be evaluated by Equation (1) as a function of the external torque $\mathrm{T}(\mathrm{Nmm})$ to be transmitted:

$$
\mathrm{F}_{\mathrm{u}}=\frac{\mathrm{T}}{\mathrm{R}_{\mathrm{m}}}
$$

Neglecting the effect of friction, for a tooth angle of $60^{\circ}$ (in Hirth connection this angle is fixed to this value) the axial force generated by the coupling is given by Equation (2):

$$
\mathrm{F}_{\mathrm{a}}=\mathrm{F}_{\mathrm{u}} \cdot \tan \left(\frac{\pi}{6}\right)
$$

The axial force can be produced, for example, by means of one or more bolts that must be accurately dimensioned [15-19]. The tooth is calculated against bending stress $\sigma_{\mathrm{b}}(\mathrm{MPa})$, approximating the trapezoidal section at the base by a rectangular one, as reported in Equation (3), where $\mathrm{z}$ is the number of teeth:

$$
\sigma_{\mathrm{b}}=\frac{6 \cdot \frac{\mathrm{Fu}_{\mathrm{u}}}{\mathrm{z}} \cdot \mathrm{h}_{\mathrm{G}}}{\mathrm{L} \cdot\left(\frac{\mathrm{a}^{\prime}+\mathrm{a}^{\prime \prime}}{2}\right)^{2}} \leq \sigma_{\mathrm{b} \_ \text {ref }}
$$

The reference values for the bending stress $\sigma_{b_{-} \text {ref }}(\mathrm{MPa})$ are reported in Table 1 , based on the assumption of a minimum root radius $(r>0.3 \mathrm{~mm}[14])$. 

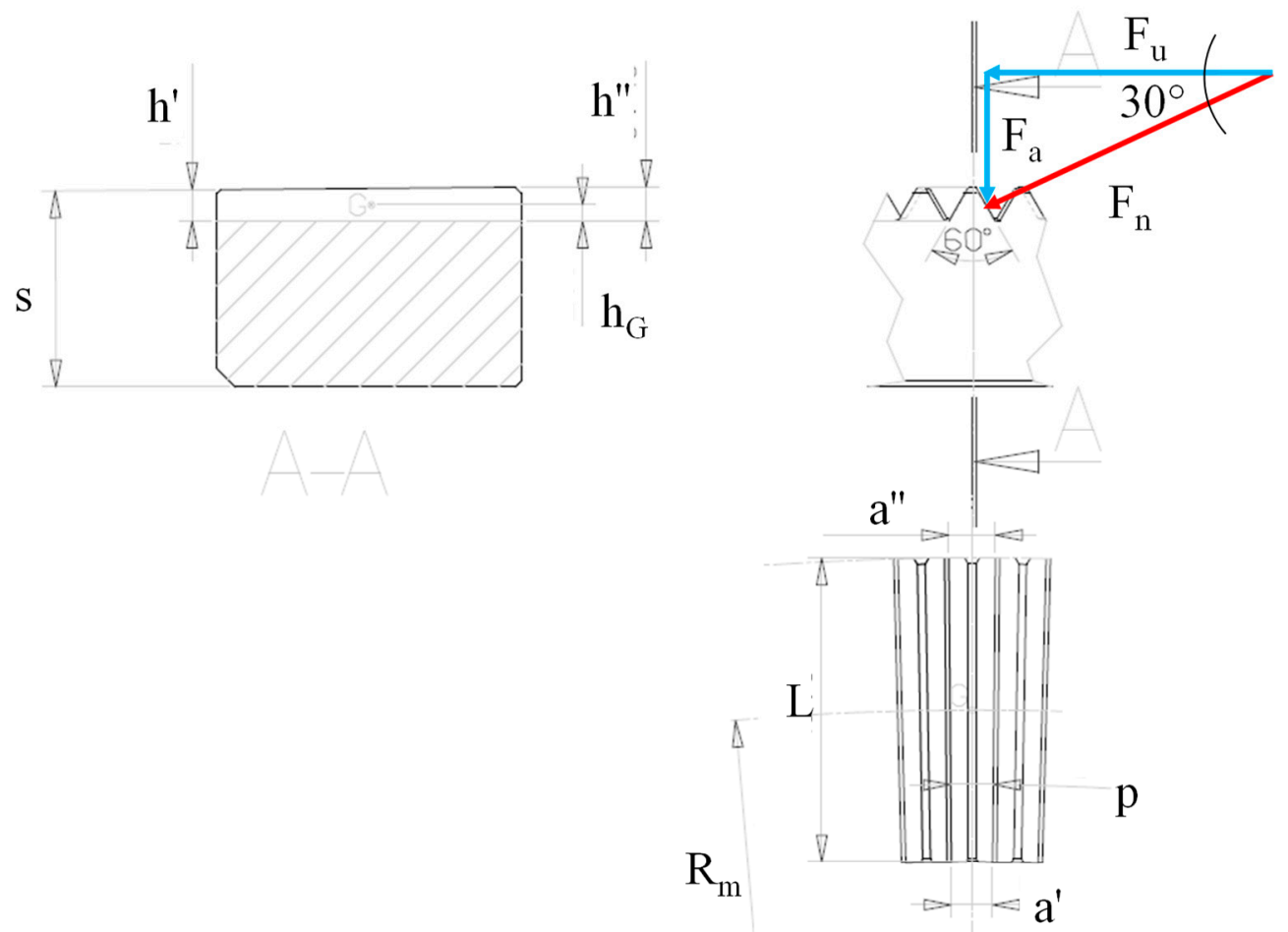

$\mathrm{h}_{\mathrm{G}}$

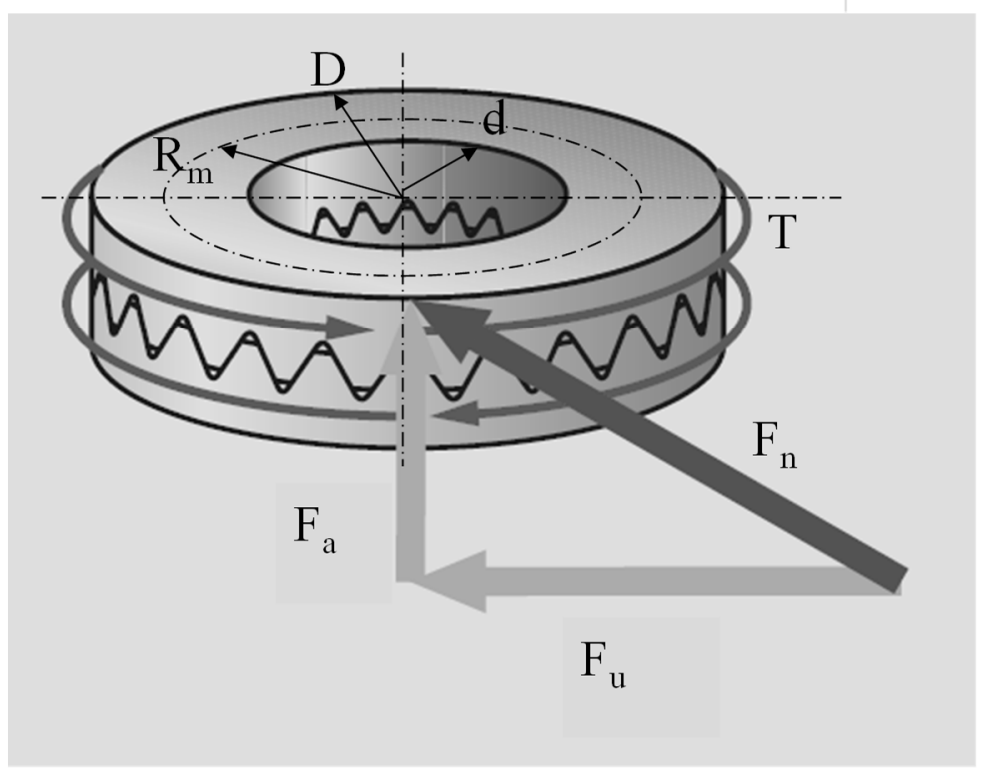

Figure 3. Nomenclature and forces acting on the tooth.

Table 1. Allowable stresses $\left(\sigma_{b_{-} \text {ref }}\right.$ and $\tau_{-}$ref $)$for carbon steel and for alloyed steels for base radius $r>$ $0.3 \mathrm{~mm}[14,20]$.

\begin{tabular}{ccccc}
\hline \multirow{2}{*}{ Type of Stress } & \multicolumn{2}{c}{ Carbon Steel } & \multicolumn{2}{c}{$\begin{array}{c}\text { Alloyed Steel } \\
\text { Cr-Ni and Cr-Mo }\end{array}$} \\
\cline { 2 - 5 } & $\boldsymbol{\sigma}_{\mathbf{b} \_ \text {ref }} \mathbf{( M P a )}$ & $\boldsymbol{\tau}_{\text {_ref }} \mathbf{( M P a )}$ & $\boldsymbol{\sigma}_{\mathbf{b} \_ \text {ref }} \mathbf{( M P a )}$ & $\boldsymbol{\tau}_{\text {ref }} \mathbf{( M P a )}$ \\
\hline No Shocks & 90 & 33.5 & 120 & 44.5 \\
With shocks & 50 & 18.5 & 70 & 26 \\
With shocks and with & 35 & 13 & 50 & 18.5 \\
torsional vibration & & & & \\
\hline
\end{tabular}


Technical German literature [20] provides a further formula in Equation (4) that is able to relate the torque $\mathrm{T}(\mathrm{Nmm})$ to the shear stress $\tau(\mathrm{MPa})$ to be compared to the allowable values $\tau_{\text {ref }}(\mathrm{MPa})$ in Table 1.

$$
\tau=\frac{16 \cdot T}{\pi \cdot D^{3}\left[1-\left(\frac{d}{D}\right)^{4}\right]} \leq \tau_{\text {ref }}
$$

The maximum (peak) bending stress at the tooth base depends on the stress distribution along the tooth and on the root radius $r(\mathrm{~mm})$ at the base. The values reported in [14,20] are able to provide nominal values only, without considering the local stress concentration. These simplified formulae have, anyway, the advantage of having been fully experimentally validated. In the most recent years, the development and improvements of finite element analysis have made it possible to achieve a more accurate estimation of the actual peak stress in mechanical components under defined hypothesis [21,22]. These methods can also be suitable for frontal teeth couplings $[2,5,23]$. The limitation in this field is related to the lack of experimental campaigns on real components, in order to relate the stress peak to the actual response of the Hirth connection. This is likely to be affected by several factors: the force acting on each tooth, the contact area, the holes for the installation, the friction between the teeth, the heat treatment process (case hardened teeth, not always with the same hardness), the hardness gradient on the teeth and the mechanical residual stresses due to the grinding operations.

Besides the analysis of Matzke, the technical literature on Hirth rings provides some more data for the designer, which are reported below. The calculation method is based on the assumption that the external torque $T(N m m)$ generates the tangential force $F_{u}(N)$ (Equation (1)). $F_{u}$ generates, in turn, the axial force $\mathrm{F}_{\mathrm{a}}(\mathrm{N})$ (Equation (2)). This axial force $\mathrm{F}_{\mathrm{a}}$ must be absorbed by preloading devices, such as disk springs, hydraulic pistons or bolts. The required pre-load $\mathrm{F}_{\mathrm{v}-\mathrm{a}}(\mathrm{N})$ is calculated, introducing a safety factor $\vee$ (Equation (5)):

$$
\mathrm{F}_{\mathrm{v}-\mathrm{a}}=\mathrm{F}_{\mathrm{a}} \cdot \mathrm{v} v=1.8 \ldots 3
$$

When compressed together, the teeth support each other if the preload $\mathrm{F}_{\mathrm{va}}(\mathrm{N})$ is high enough. The varying loads on the tooth flanks result merely in a slightly irregular distribution of the pressure preload in the tooth root cross-section generating a maximum pressure $\mathrm{p}_{\max }(\mathrm{MPa})$ according to Equation (6). In this equation (see Figure 4) $\mathrm{A}_{\mathrm{z}}\left(\mathrm{mm}^{2}\right)$ is the effective tooth flank area, D and $\mathrm{d}(\mathrm{mm})$ are the outer and the inner diameters of the teeth, $d_{L}(\mathrm{~mm})$ is the fixing hole diameter, $\mathrm{n}_{\mathrm{b}}$ is the number of bolts in the teeth surface, $r(\mathrm{~mm})$ is the tooth root radius, $\mathrm{s}(\mathrm{mm})$ is the crown clearance, $\mathrm{z}$ the number of the teeth and $\eta_{z}$ is the load bearing percentage ( 0.65 for milled teeth or 0.75 for grinded teeth). Under compression, with a high enough $\mathrm{F}_{\mathrm{va}}$ load and with no transmission of torque, this load is equally distributed on both faces of each tooth. Conversely, when transmitting the torque $T$, the pressure rises on one face of the tooth and drops down on the other. The maximum pressure $p_{\max }$ $(\mathrm{MPa})$ is calculated as follows:

$$
\left\{\begin{array}{l}
\mathrm{p}_{\max }=\frac{\mathrm{F}_{\mathrm{v}-\mathrm{a}}+\mathrm{F}_{\mathrm{a}}}{\mathrm{A}_{\mathrm{z}}} \\
\mathrm{A}_{\mathrm{z}}=\left(\mathrm{D}-\mathrm{d}-\frac{\mathrm{n}_{\mathrm{b}} \cdot \mathrm{d}_{\mathrm{L}}^{2}}{\mathrm{D}+\mathrm{d}}\right) \cdot\left[\frac{\pi}{4}(\mathrm{D}+\mathrm{d})-1.155 \cdot \mathrm{z} \cdot(\mathrm{r}+\mathrm{s})\right] \cdot \eta_{\mathrm{z}}
\end{array}\right.
$$

Concerning the geometry, the manufacturers offer a fixed parametric rule, in order to calculate the tooth height $\mathrm{h}(\mathrm{mm})$ in correspondence of the mean radius $\mathrm{R}_{\mathrm{m}}(\mathrm{mm})$ (see Figure 4, Equation $(7)$ and Table 2).

$$
\mathrm{h}=\mathrm{c} \cdot \mathrm{D}-(2 \cdot \mathrm{r}+\mathrm{s})
$$



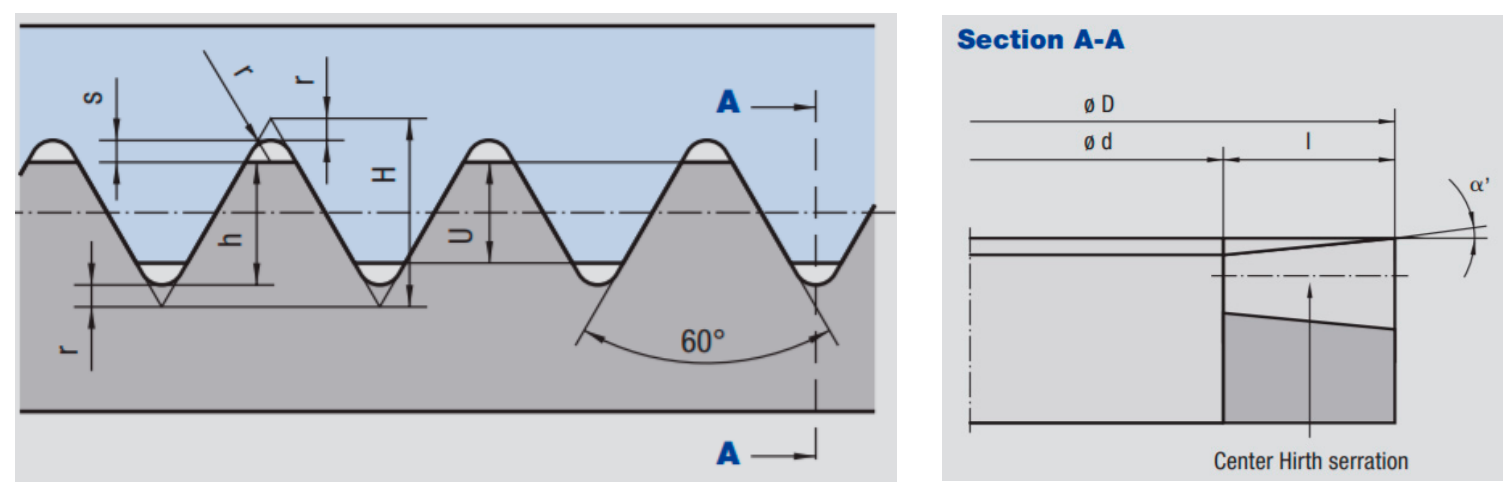

Figure 4. Geometric parameters from the manufacturer "Voith-Turbo Gmbh".

Table 2. Tables provided by the manufacturer "Voith-Turbo Gmbh" for the proper choice of Factor c and of the crown clearance s.

\begin{tabular}{cc}
\hline Number of Teeth $\mathbf{z}$ & Factor c \\
\hline 12 & 0.234 \\
24 & 0.114 \\
36 & 0.075 \\
48 & 0.056 \\
60 & 0.045 \\
72 & 0.037 \\
96 & 0.028 \\
120 & 0.022 \\
144 & 0.018 \\
180 & 0.015 \\
240 & 0.011 \\
288 & 0.009 \\
360 & 0.007 \\
720 & 0.003 \\
\hline Tooth Root Radius $\mathbf{r}$ & Crown Clearance s \\
\hline 0.3 & 0.4 \\
0.6 & 0.6 \\
1.0 & 1.0 \\
1.6 & 1.6 \\
2.5 & 2.5 \\
\hline
\end{tabular}

Finally, concerning Hirth ring manufacturing, the most widely used materials are alloyed steels for quenching and tempering with $\mathrm{Cr}$ and Mo, namely $42 \mathrm{CrMo}_{4}$ (W. Nr. 1.7225 ) or $34 \mathrm{Cr}_{4}$ (W. Nr. 1.7033). Their production cycle is based on the following operations: turning, drilling the fixing holes and pins, milling the teeth, inductive hardening of the tooth area (hardening in the range $52 \ldots$ $60 \mathrm{HRC}$ ), rough grinding of the teeth, finishing grinding of the teeth and of the reference surfaces, dimensional checking, finishing the pin holes, final checking and production of measuring report. An example of a measuring report is shown in Table 3.

The high precision and costs of these components allow an indexing accuracy of $+/-2$ " (arcsec), a repeat accuracy $<0.001 \mathrm{~mm}$, a self-centering capability, a high wear resistance and a long-term service life. 
Table 3. Measuring report of Hirth rings engagements.

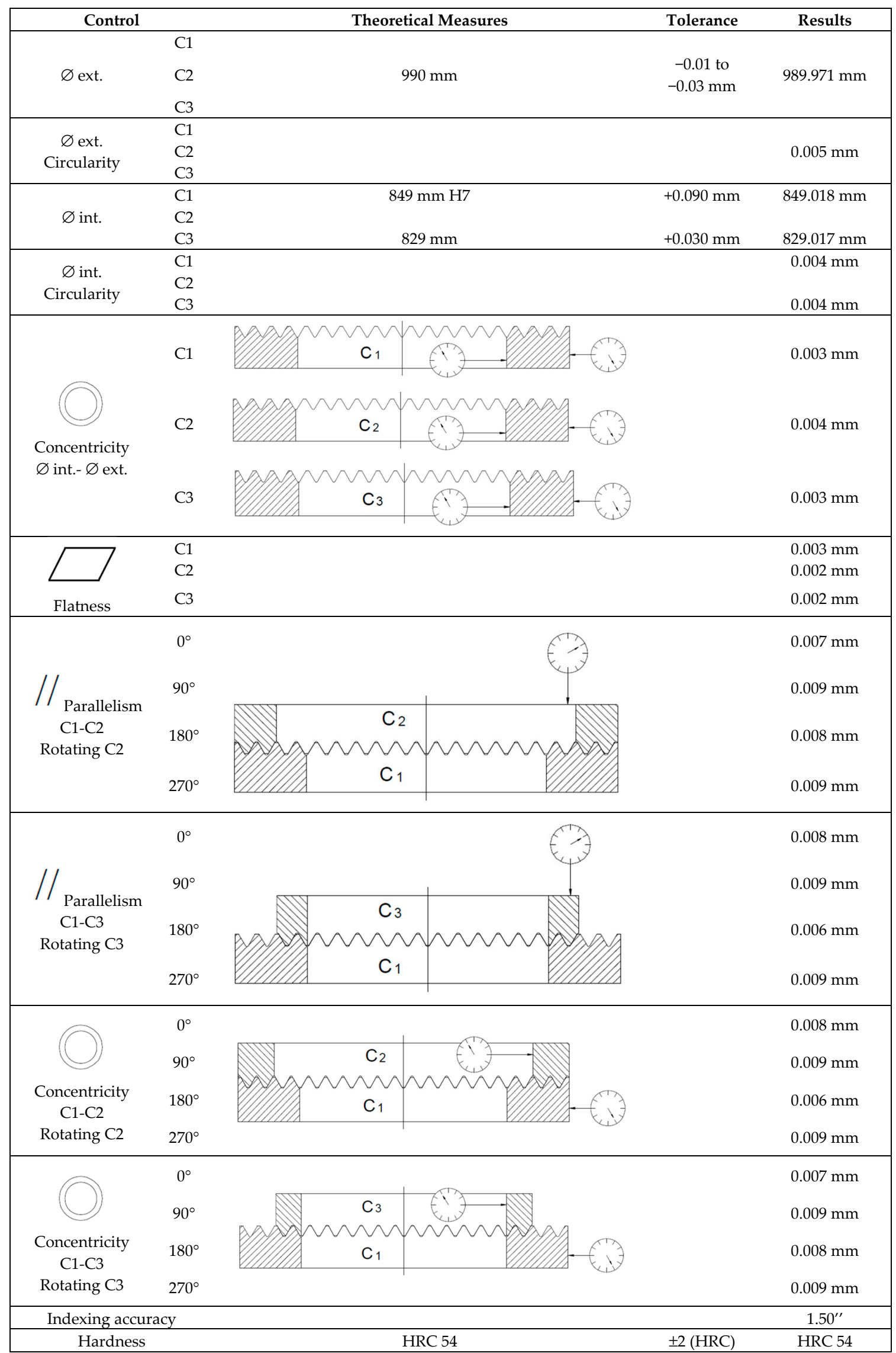




\section{Improved Calculation}

\subsection{Effect of Friction}

The effect of friction between the mating teeth is not taken into account in the standard procedure. This effect is quite easy to be implemented and it is very important since it is detrimental to safety: according to Equation (8), in the presence of friction (angle of friction $\rho\left({ }^{\circ}\right)$ ), with the same axial force, the actual transmission load $\mathrm{F}_{\mathrm{u}, \mu}(\mathrm{N})$ is reduced if the pre-load remains unchanged. Otherwise, a higher axial pre-load becomes necessary to achieve the same transmission. The coefficient of friction $\mu=\tan (\rho)$ in compression couplings can be evaluated by experimental tests, such as those reported in $[24,25]$, and can may range between 0.1 and 0.3 for smooth surfaces.

$$
\left\{\begin{array}{l}
\mathrm{F}_{\mathrm{u}, \mu}=\frac{\mathrm{F}_{\mathrm{a}}}{\tan \left(\frac{\pi}{6}+\rho\right)} \\
\mathrm{F}_{\mathrm{u}, \mu}=\mathrm{F}_{\mathrm{u}} \cdot \mathrm{KK}=\frac{\tan \left(\frac{\pi}{6}\right)}{\tan \left(\frac{\pi}{6}+\rho\right)}
\end{array}\right.
$$

In Figure 5 the reduction factor for the transmitted load (K, Equation (8)) is reported as a function of the angle of friction.

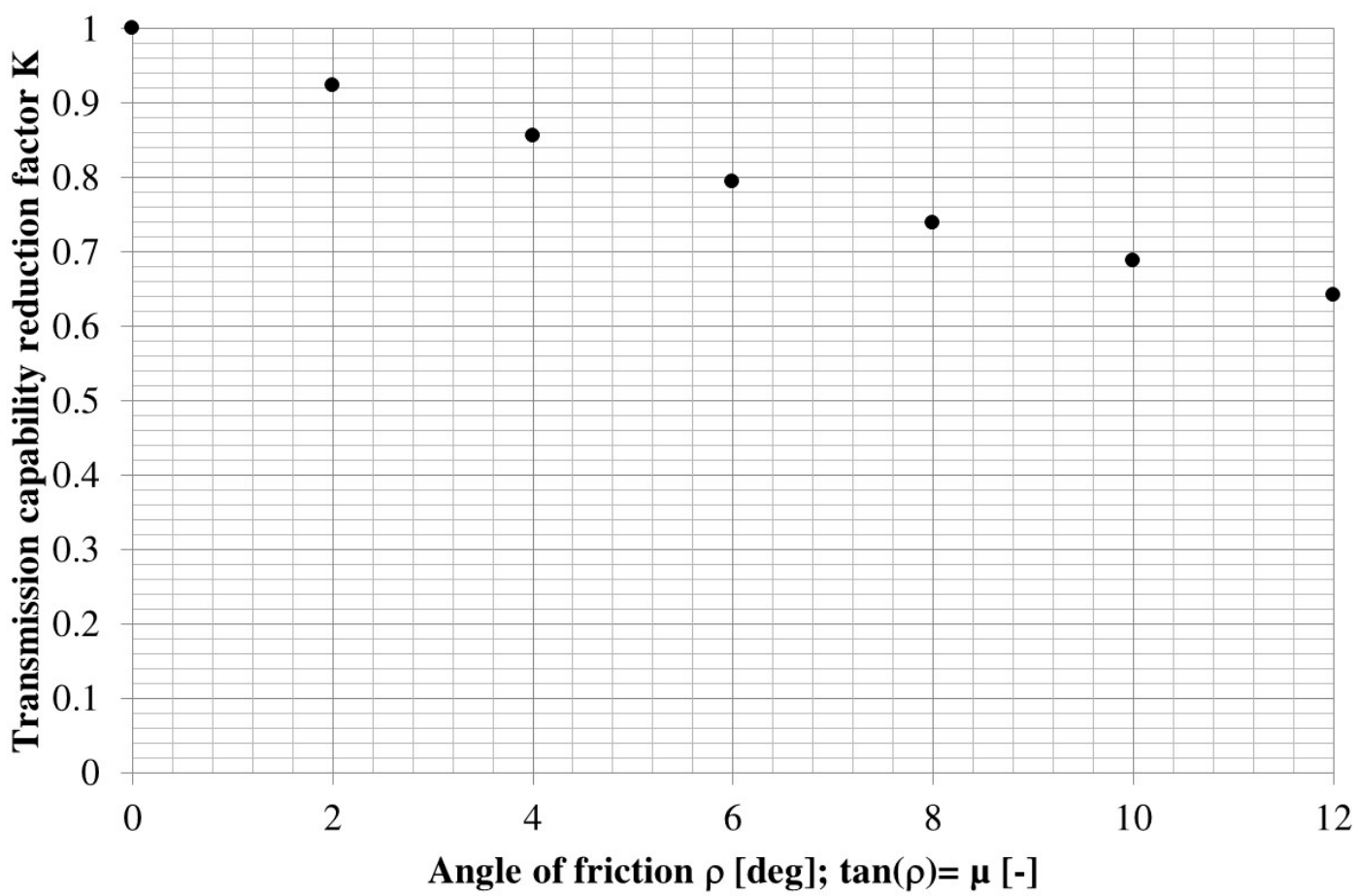

Figure 5. Reduction factor of transmission load $\mathrm{K}$ as a function of the angle of friction $\rho$.

The pressure between the teeth is also affected by the coefficient of friction, but with a lower effect. By non-linear finite element analyses (non-linear due to sliding elements in contact), it is possible to calculate the percentage reduction factor for the tooth pressure $\left(\mathrm{K}_{\mathrm{p}}\right)$ with respect to the value calculated by Equation (6)) and, then, to plot it in the diagram of Figure 6. In the case of negligible friction $(\mu=0)$ the difference between Equation (6) and the numerical investigation is almost equal to zero. 


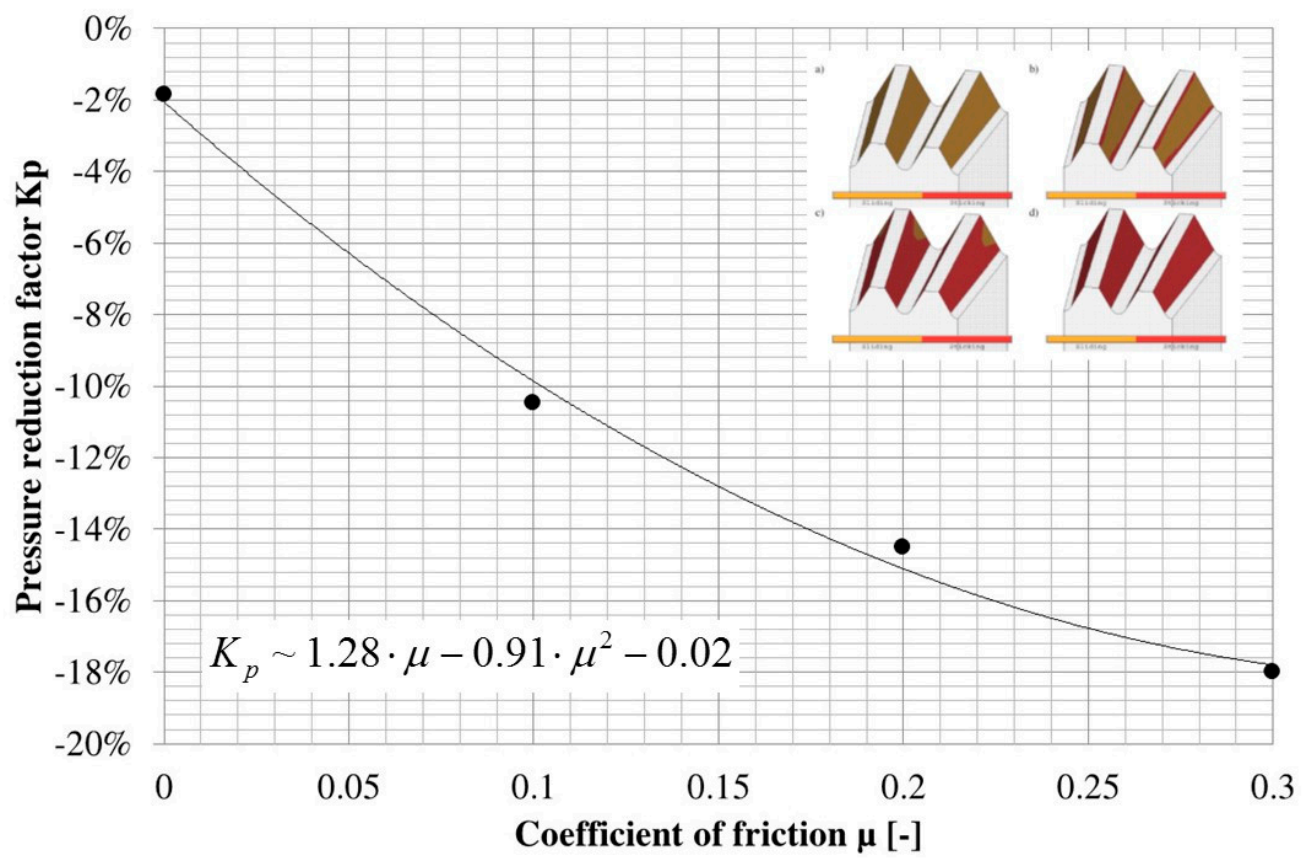

Figure 6. Reduction factor for the tooth pressure $K_{p}$ as a function of the coefficient of friction $\mu$.

\subsection{Self-Centering Capability}

It is well known that Hirth connections have self-centering capability. This feature is particularly important in all the applications in which the rings must be disengaged during their life. A very common example is the turntables of the machine tools. In a multi-station round transfer machine the sequence of two actions takes place: (i) the table is fixed with the Hirth rings engaged, when the machining operations are running (the rigid connection ensures the accomplishment of the strict geometrical tolerances of the machined parts); (ii) after the end of the machining tasks in one station, the table must rotate to the next station: for this purpose, the connections must be disengaged. Following the alignment with the next station, the rotary table must then be engaged and constrained again to let new machining operations start. Repeatability, accuracy and self-centering capability are necessary to produce parts compliant with very strict geometrical tolerances. Figure 7a explains the aforementioned cycle with regard to a triple Hirth connection: ring \#1 is fixed in the machine bench and it is the reference for the accurate position (it does not move). Ring \#2 is connected to the rotary table, so it moves (rotates) with the table (the table must return always in the same position with respect to the machine bench). Ring \#3 is responsible for engaging/disengaging and for accurate position. When ring \#3 moves up, the table is disengaged and can be rotated from station to station by a motor and a gearbox. Once the table gets close to the expected position, the motor is stopped in a pre-positioning area (as the allowance in the gears of the gearbox does not allow for a precise positioning), so ring \#3 can move down. During its movement from the top to the bottom, since the teeth are conical from exterior to interior (Figure 3), ring \#3 initially fits the reference ring \#1 (so, ring \#3 is aligned with ring \#1). Afterwards, it fits the movable ring \#2 that is therefore taken in the correct position (so, ring\#2 is also aligned with ring \#1). For the correct positioning of ring \#2, the axial force $F_{a}(N)$ has to be high enough to move all the weight related to the rotary table on the bearing surface. The calculation of the self-centering force $\mathrm{F}_{\mathrm{C}}(\mathrm{N})$, which is not provided in the technical or in the scientific literature, will be shown in the following. 


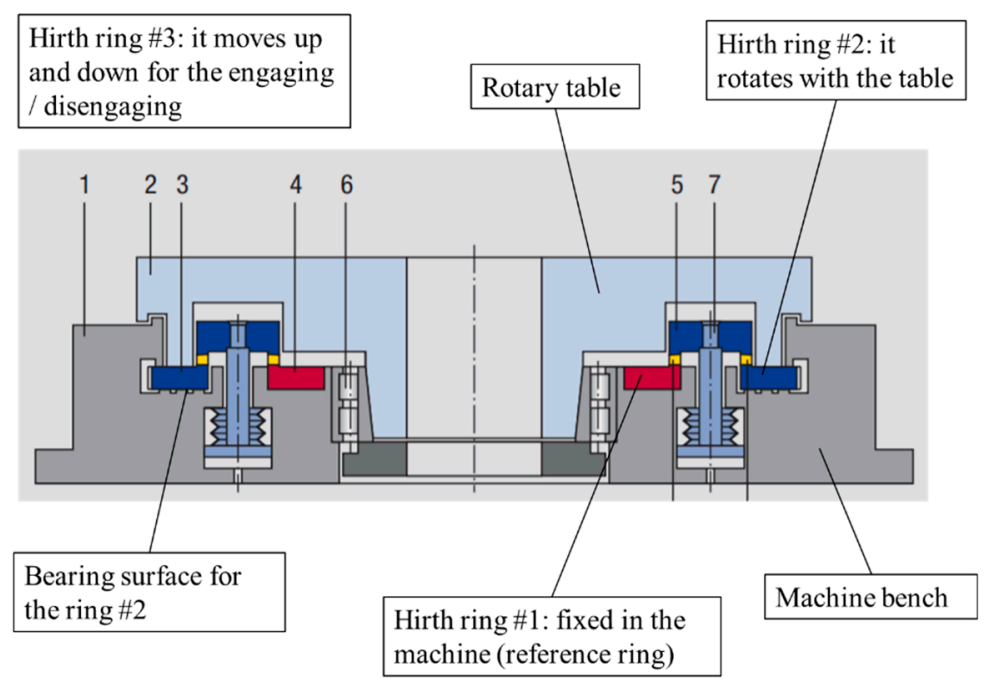

(a)
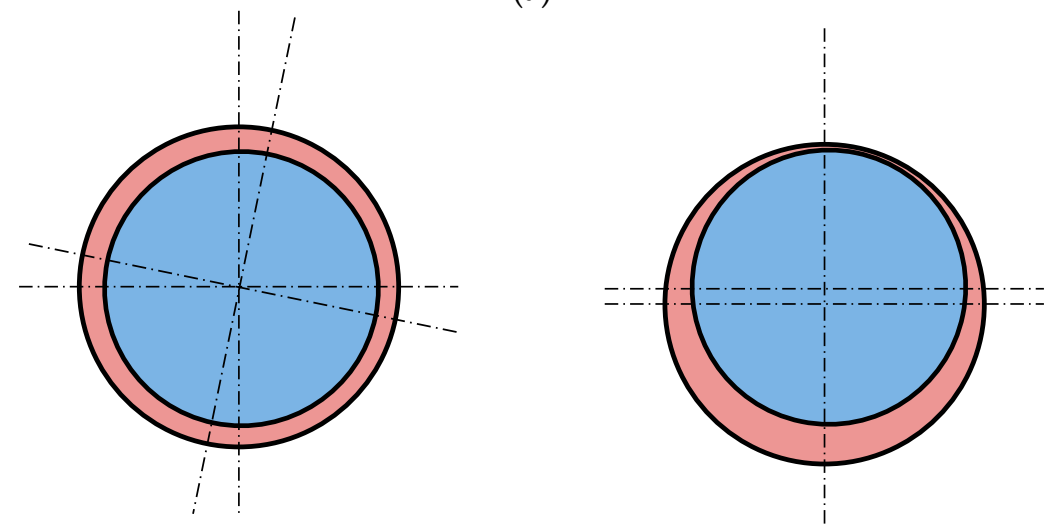

(b)

Figure 7. (a) Example of rotary table for the transfer machine tool; (b) position of ring \#2 before engaging phase: left—-the angle has to be adjusted; right—-the center has to be adjusted.

Three possible scenarios before the engaging phase have to be considered (see Figure $7 \mathrm{~b}$ ): (i) the fixed and the rotating ring have the same center and just have a different angular position; (ii) the fixed and the rotating ring have different centers and the same angular position; (iii) a combination of (i) and (ii).

Different configurations and alignments of teeth are highlighted in Figure 8: in case (a) the teeth of the fixed and rotating rings are engaged: they are all aligned and the space between the rings is constant (the upper ring is not represented); in case (b) before the engagement of the upper ring, there is an angular misalignment of the rotating ring. Since the rings have the same center, the space between the two rings is constant. In case (c) before the engagement of the upper ring, the two centers are not aligned (the self-centering force $\mathrm{F}_{\mathrm{c}}$ should recreate the (a) condition). As a consequence, the space between the two rings is not constant on the $360^{\circ}$ span and furthermore an angular misalignment $\gamma\left({ }^{\circ}\right)$ of the teeth also occurs: this is variable on the $360^{\circ}$ span.

The conditions shown in Figure 8a,b (cases a and b) do not deserve any particular analytical evaluation. Conversely, the effect of the center misalignment $\mathrm{c}(\mathrm{mm})$ (Figure 8c, case c) requires a detailed analysis. According to Figure 9, the trend of the misalignment angle $\gamma\left({ }^{\circ}\right)$ around the $360^{\circ}$ $\left(\theta\right.$ between $0^{\circ}$ and $360^{\circ}$ ) span is yielded by Equation (9):

$$
\left\{\begin{array}{l}
r=\sqrt{R^{2}+c^{2}-2 \cdot R \cdot c \cdot \cos (\theta)} \\
\gamma=\arcsin \left[\frac{c}{r} \cdot \sin (\theta)\right]
\end{array}\right.
$$




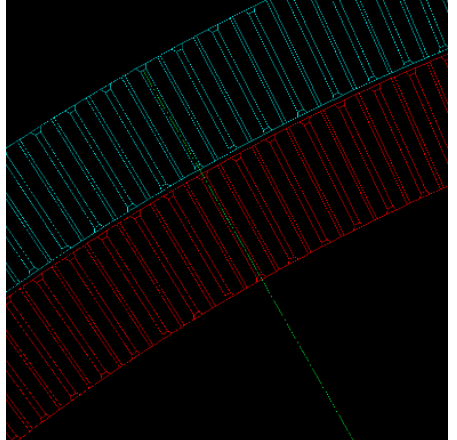

(a)

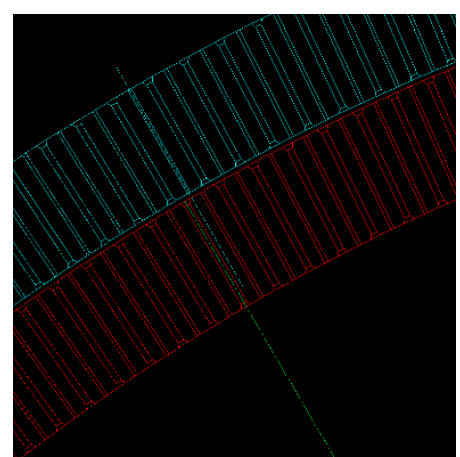

(b)

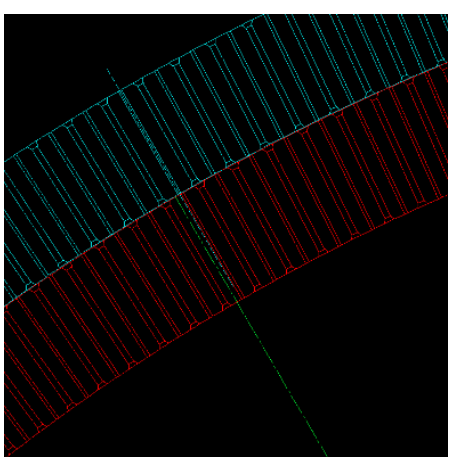

(c)

Figure 8. (a) Ring \#1 and ring \#2 engaged correctly; (b) before engagement: pure angular misalignment; (c) before engagement: center misalignment (which also generates angular misalignment).

As an example, for a ring diameter $\mathrm{R}=450 \mathrm{~mm}$, a center displacement $\mathrm{c}=1 \mathrm{~mm}$, when the angle $\theta$ is $29.5^{\circ}$, the angular misalignment $\gamma$ is $0.063^{\circ}\left(\sim 4^{\prime}\right)$; for $\theta=89.5^{\circ}$, the angular misalignment $\gamma$ is $0.127^{\circ}$ $\left(\sim 8^{\prime}\right)$. These results have also been checked by CAD system (Figure $\left.9 \mathrm{~b}\right)$. The whole trend is reported in Figure $9 \mathrm{c}$ for the interval $0-90^{\circ}$, provided that the function is symmetric every $90^{\circ}$.

In order to achieve the correct engagement, the following condition in Equation (10) must be fulfilled (the maximum misalignment $\gamma$ must be within the angular step of the teeth):

$$
\gamma_{\max }<\frac{360^{\circ}}{\mathrm{z}}
$$

Combining Equations (9) and (10), it is possible to work out the upper threshold $\mathrm{c}_{\max }(\mathrm{mm})$ for the displacement of the center of the rotating ring, in order to ensure the correct position (Equation (11)). The maximum misalignment $\gamma$ for $\theta=90^{\circ}$ (see Figure 9c) is considered for processing.

$$
\mathrm{c}_{\max }=\mathrm{r} \cdot \sin \left(\frac{360^{\circ}}{\mathrm{Z}}\right) \approx \mathrm{R} \cdot \sin \left(\frac{360^{\circ}}{\mathrm{Z}}\right)
$$

During the design phase, clearances and gaps in bearings, sealings and gears must accomplish this condition and the sum of all the assembly tolerances must be within $c_{\max }$.

Unfortunately, the condition reported in Equation (11) is not sufficient to warrant the actual occurrence of self-centering; an additional force analysis and assessment is necessary. As a matter of fact, the self-centering force $F_{c}(N)$ must be high enough to overcome all the friction forces, and to consequently move the rotating ring (along with the overall mass) towards its correct position. The self-centering force $F_{c}(N)$ can be calculated by means of Equation (12), where every single tooth provides a different contribution, as a function of its angular position:

$$
F_{C}=4 \cdot \sum_{i=0}^{z / 4} \frac{F_{a}}{z \tan \left(\frac{\pi}{6}+\rho\right)} \cdot \sin \left(i \cdot \frac{360^{\circ}}{z}\right)=K_{C} \cdot \frac{F_{a}}{\tan \left(\frac{\pi}{6}+\rho\right)}
$$

with $K_{C}$ equal to 0.642 for $z=360 ; 0.650$ for $z=144 ; 0.664$ for $z=72$. 


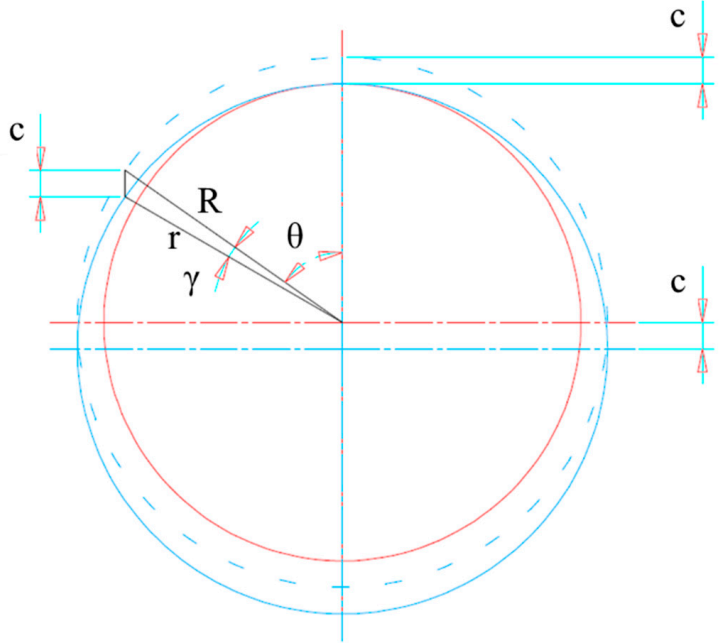

(a)

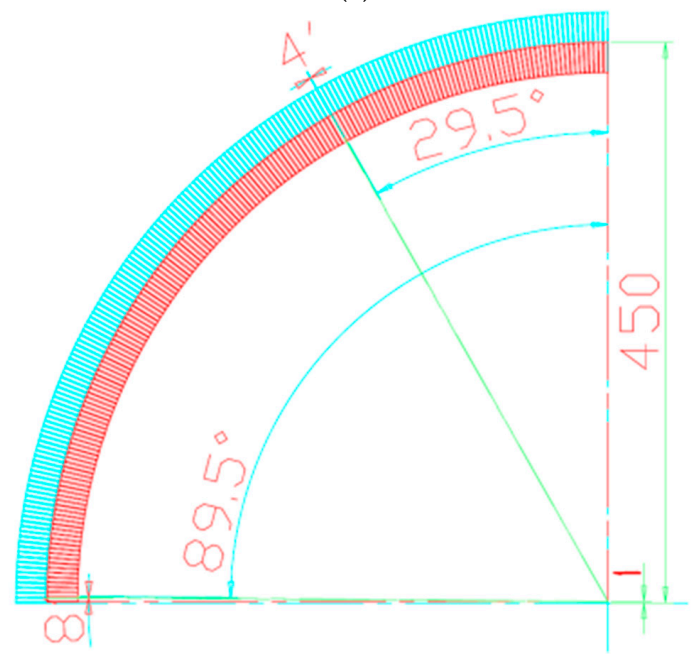

(b)

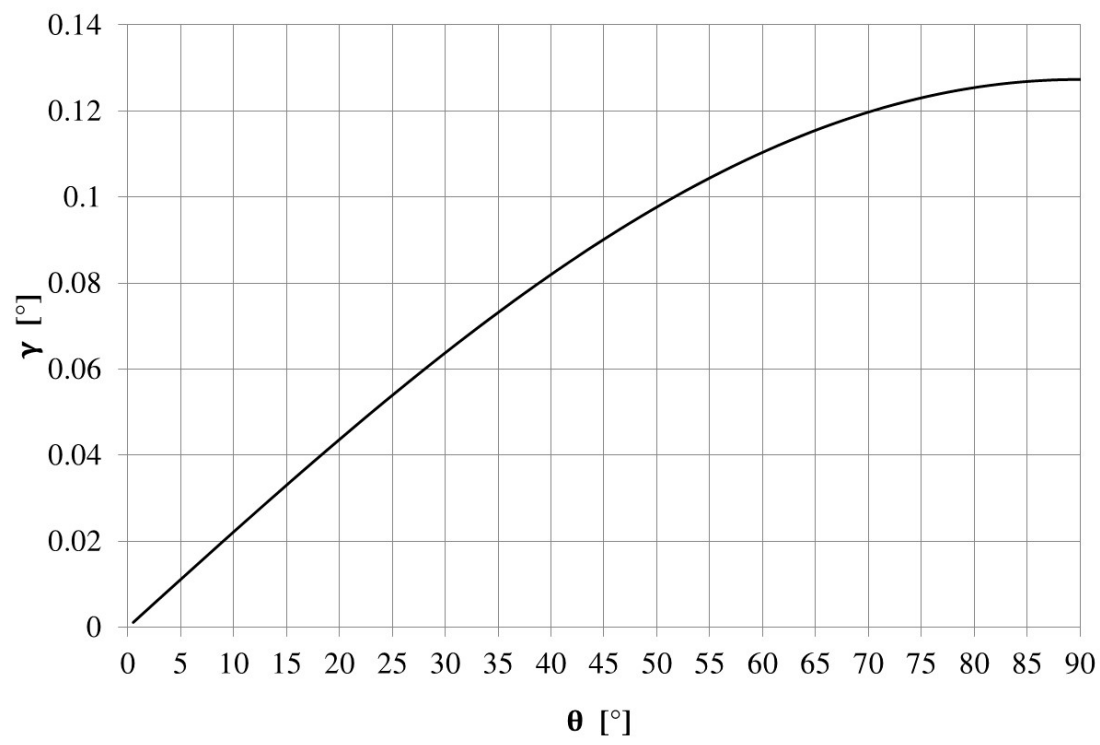

(c)

Figure 9. (a) Sketch for the evaluation of the misalignment angle $\gamma$; (b) practical example via CAD system and (c) related trend of $\gamma$ as a function of $\theta$. 


\section{Experimental Tests}

Experimental tests on a triple Hirth ring connection with a mean diameter of $900 \mathrm{~mm}$ and $\mathrm{z}=360$ have been performed in order to check the proposed formulas (Figure 10).

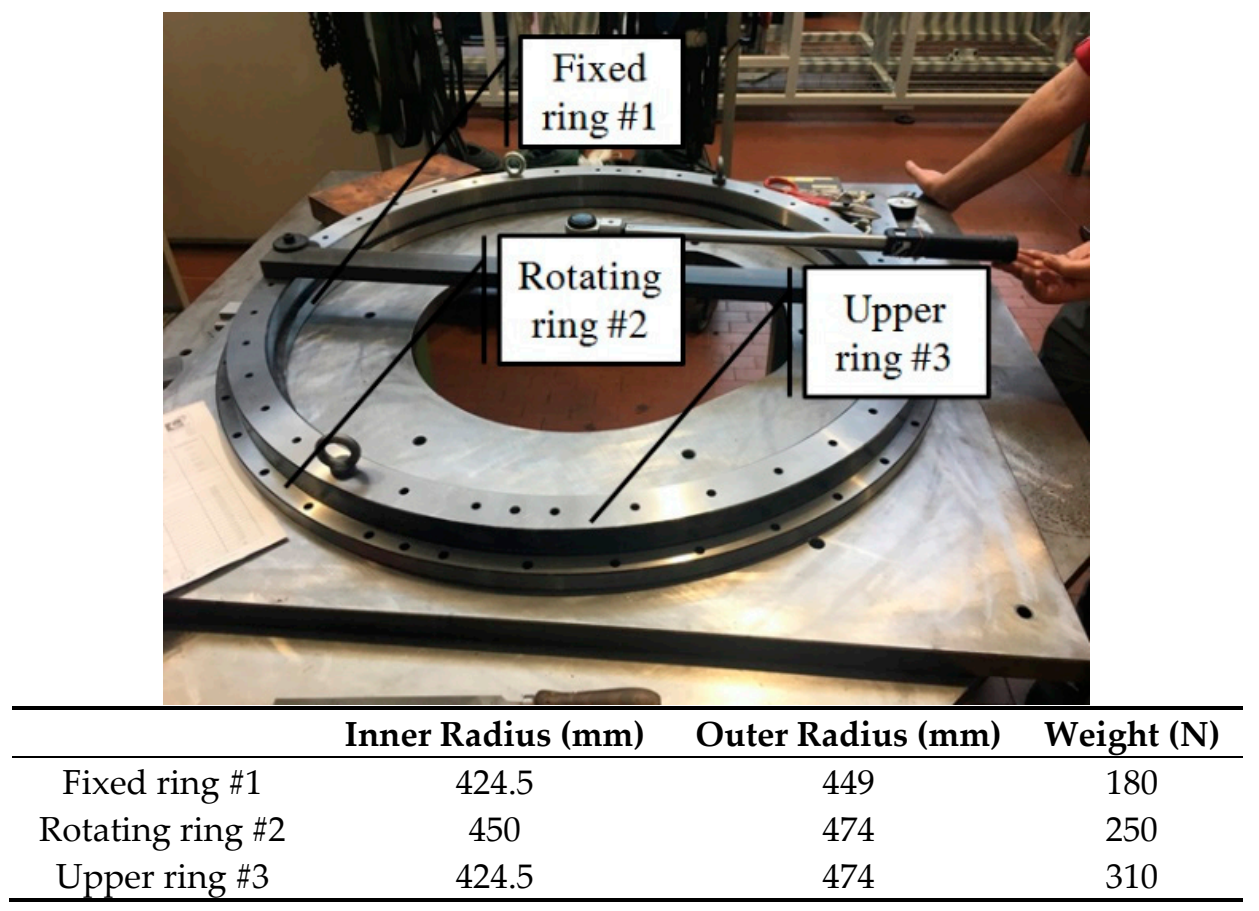

Figure 10. Hirth ring connection with a mean diameter of $900 \mathrm{~mm}$ and $\mathrm{z}=360$.

At first, the static coefficient of friction $\mu$ in the bearing surface of the rotating ring (see Figure 7a) has been evaluated, in order to get its actual value. Thanks to a dynamometer, the radial force to be applied to move the rotating ring (merely supported on its bearing surface, without engagement) has been detected. The static coefficient of friction $\mu$ has therefore been calculated (five repeated tests) as the ratio between the radial force and its weight. The value of the static coefficient of friction $\mu$ is equal to $0.204+/-0.012 ; \mu \sim 0.2$ was consequently used for the calculation. Regarding the own weight of the upper ring $(310 \mathrm{~N})$ as the axial pre-loading force, $\mathrm{F}_{\mathrm{a}}$, and considering the angle of friction $\rho$ between the teeth of $11.3^{\circ}(\mu=0.2)$, a self-centering force $F_{c}=\sim 225 \mathrm{~N}$ is yielded by Equation (12). The frictional resistance force $R_{\mu}(\mathrm{N})$ can be evaluated as the overall sum of the weights of the rotating and upper rings (i.e., the rings that must be moved into the correct position, leveraging the position of the fixed ring), multiplied by the aforementioned coefficient of friction in the bearing surface; a force $\mathrm{R}_{\mu}=\sim 112 \mathrm{~N}$ is determined (reference sketch in Figure 11). The experimental test has shown the self-centering capability: the rings were able to shift to the correct engaged position, being $F_{c}>R_{\mu}$. To fully validate the correctness of the formulation, an additional external force in the radial direction $F_{r, e}$ (N) has been applied and measured by the same dynamometer (Figure 12). This force can be directly combined with the frictional force $R_{\mu}$ (it can be regarded as an extra-frictional force), because it is able to work against the self-centering force Fc. In this way, the self-centering capability has been evaluated accurately, step-by-step increasing the force $F_{r, e}$, until $\left(R_{\mu}+F_{r, e}\right)$ equalized the available $F_{c}$. The retrieved results are reported in Table 4; it can be highlighted that up to $F_{r, e}=100 \mathrm{~N}$, the self-centering force is able to move the rings into the correct position, whereas in the range between $\mathrm{F}_{\mathrm{r}, \mathrm{e}}$ $=100$ and $120 \mathrm{~N}$, the self-centering capability is equal to the resistance forces: therefore, no movement occurs. As a matter of a fact, the calculated value of $\mathrm{FC}_{\mathrm{C}}=\sim 225 \mathrm{~N}$ (Equation (12)) is reliable since the addition of $R_{\mu}$ and $F_{r, e}$ yields $\sim 112+120=232 \mathrm{~N}$. 

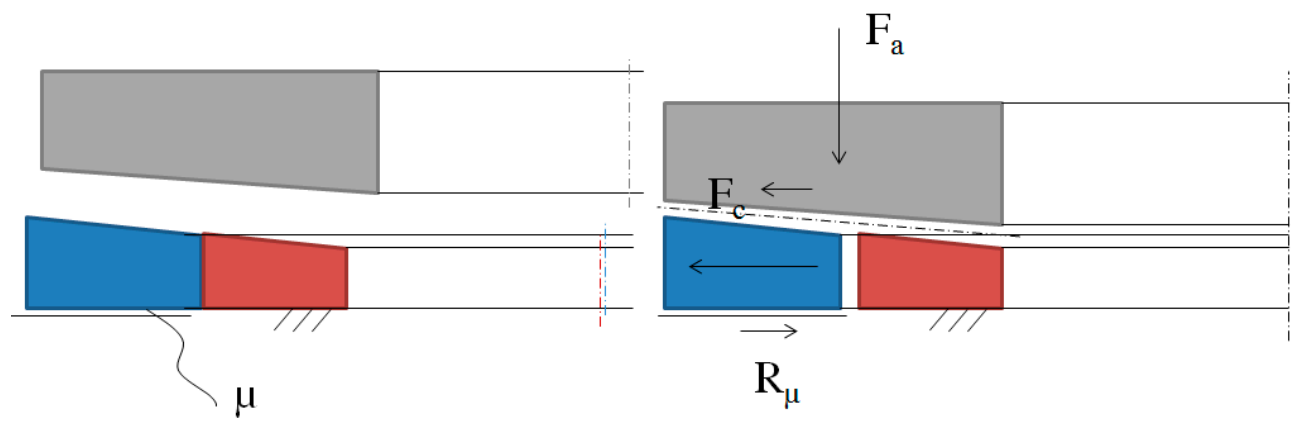

Figure 11. Hirth self-centering action.

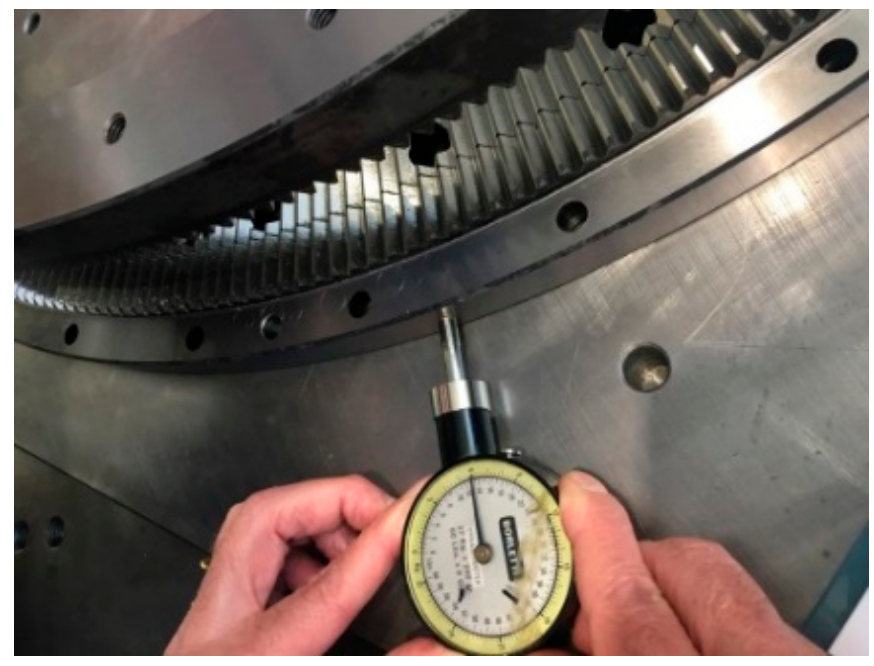

Figure 12. Self-centering capability with the presence of $R_{\mu}$ and $F_{r, e}$.

Table 4. Experimental verification of the self-centering capability.

\begin{tabular}{cc}
\hline Additional External Radial Load $\mathrm{F}_{\mathrm{r}, \mathrm{e}}(\mathbf{N})$ & Self-Centering Capability $(\mathrm{YES} / \mathrm{NO})$ \\
\hline 20 & $\mathrm{YES} \odot$ \\
40 & $\mathrm{YES} \odot$ \\
60 & $\mathrm{YES} \odot$ \\
80 & $\mathrm{YES} \odot$ \\
100 & $\mathrm{YES} \odot$ \\
120 & $\mathrm{NO} \odot$ \\
\hline
\end{tabular}

\section{Case Study}

The case study proposed in this section refers to the rotary table of a big transfer machine tool, which has a Hirth ring connection with the same geometrical dimensions of that tested in the previous section. The present work moves from some issues related to the actual positioning of the rotary table (with concern regarding the loss of self-centering capability) after several years of work. After disassembling the rotary table, it was found that a lot of rust was present both in the teeth and in the bearing surface of the rotating ring (Figure 13). The presence of rust, as highlighted in [24,25], significantly increases the coefficient of friction, therefore reducing performance and self-centering capability. In this section, the aforementioned analytical predictive model is applied and the influence of the coefficient of friction on the actual performance is also studied. 

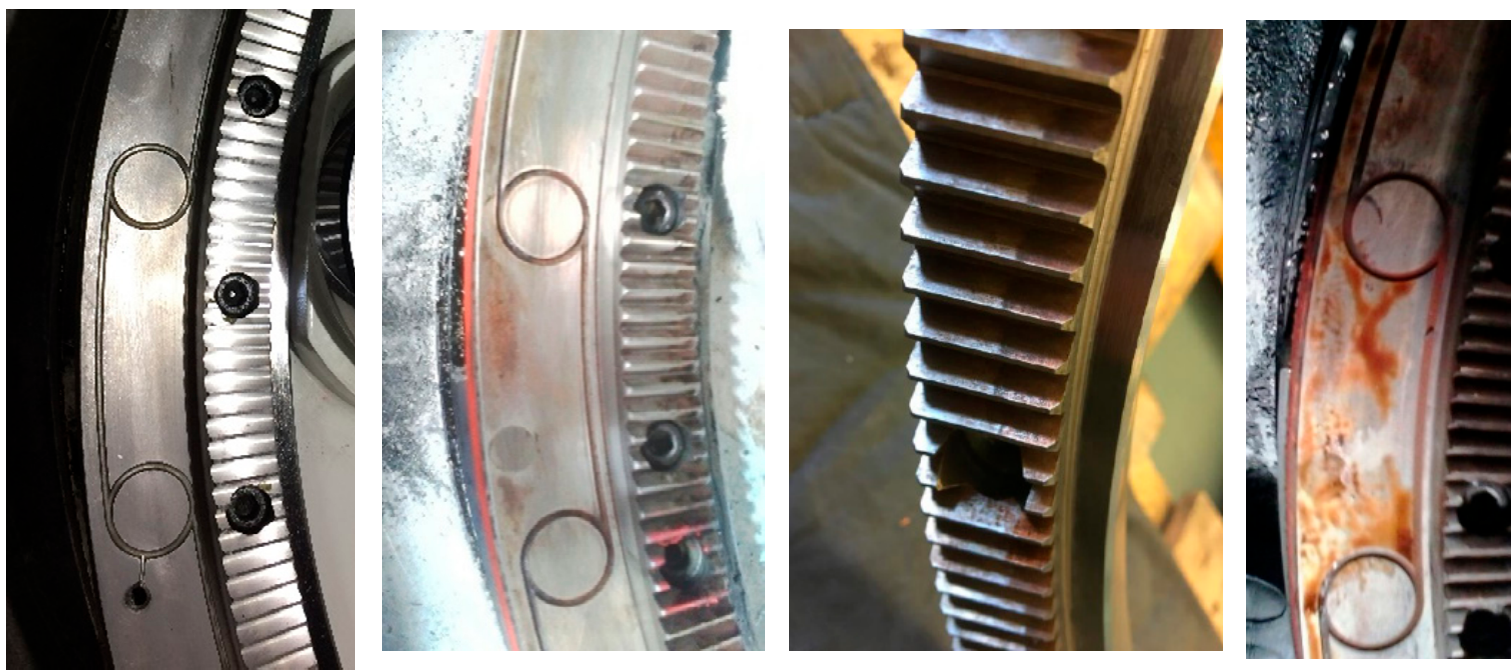

Figure 13. Comparison between the status of a new Hirth connection vs. a rusty one.

The data for the calculation are reported in Table 5.

Table 5. Calculation data for a rotary table of a transfer machine (Figure 7a).

\begin{tabular}{|c|c|c|c|c|}
\hline ID & Description & Type of Data & Value & Units \\
\hline 1 & Tooth Angle & $\begin{array}{l}\text { Input data (fixed for Hirth } \\
\text { connection) }\end{array}$ & 30 & $\circ$ \\
\hline 2 & & & 0.524 & $\mathrm{rad}$ \\
\hline 3 & Friction angle & Input data & 11.5 & $\circ$ \\
\hline 4 & & & 0.201 & $\mathrm{rad}$ \\
\hline 5 & Coefficient of friction $\mu$ & Calculated: $\mu=\tan (\rho)$ & 0.203 & \\
\hline 6 & $\begin{array}{l}\text { Maximum external tangential force to be } \\
\text { transmitted during a milling operation }\end{array}$ & Input data & 5000 & $\mathrm{~N}$ \\
\hline 7 & $\begin{array}{l}\text { Distance from the center of the tangential } \\
\text { force (radius of the rotary table) }\end{array}$ & Input data & 700 & $\mathrm{~mm}$ \\
\hline 8 & Minimum Torque $\mathrm{T}$ to be transmitted & Calculated: ID6 $\times$ ID7 & 3500 & $\mathrm{Nm}$ \\
\hline 9 & Hirth rings mean radius & Input data & 450 & $\mathrm{~mm}$ \\
\hline 10 & $\begin{array}{l}\text { Tangential force } F_{u} \text { on the Hirth } \\
\text { connection }\end{array}$ & Calculated: ID8 × 1000/ID9 & 7778 & $\mathrm{~N}$ \\
\hline 11 & Safety factor SF & Input data (reference value: $3 \ldots 5$ ) & 4 & \\
\hline 12 & $\begin{array}{l}\text { Tangential force } F_{u} \text { on the Hirth } \\
\text { connection including SF }\end{array}$ & Calculated: ID10 × ID11 & 31,111 & $\mathrm{~N}$ \\
\hline 13 & Tangential force $F_{u}$ used for the design & $\begin{array}{l}\text { Selected by the designer on the basis } \\
\text { of ID12 }\end{array}$ & 35,000 & $\mathrm{~N}$ \\
\hline 14 & Axial force $\mathrm{F}_{\mathrm{a}}$ (including friction) & Calculated (info in the paper) & 30,965 & $\mathrm{~N}$ \\
\hline 15 & Self-centering capability $F_{c}$ & Calculated (info in the paper) & 22,326 & $\mathrm{~N}$ \\
\hline 16 & $\begin{array}{l}\text { Weight of the rotary table connected to } \\
\text { the rotary ring }\end{array}$ & Input data & 40,000 & $\mathrm{~N}$ \\
\hline 17 & Frictional force $\mathrm{R}_{\mu}$ & Calculated: ID16 $\times$ ID5 & 8138 & $\mathrm{~N}$ \\
\hline 18 & $\begin{array}{l}\text { Mean sliding radius of the bearing } \\
\text { surface }\end{array}$ & Input data & 470 & $\mathrm{~mm}$ \\
\hline 19 & Frictional torque on the bearing surface & Calculated: ID17 $\times$ ID18 & 3825 & $\mathrm{Nm}$ \\
\hline 20 & $\begin{array}{l}\text { Additional frictional torque (sealings, } \\
\text { bearings, ...) }\end{array}$ & Input data & 3000 & $\mathrm{Nm}$ \\
\hline 21 & Torque $\mathrm{T}$ that Hirth rings can transmit & Calculated: ID13 $\times$ ID9 & 15,750 & $\mathrm{Nm}$ \\
\hline 22 & Frictional torque $T_{\mu}$ & Calculated: ID19 + ID20 & 6825 & $\mathrm{Nm}$ \\
\hline
\end{tabular}


Analyzing the data in Table 5, based on force balance, it is possible to highlight that the following conditions are fulfilled in the presence of a coefficient of friction $\mu=\sim 0.2$ (ID5).

- $\quad$ The condition of the minimum torque $\mathrm{T}$ to be transmitted (ID8) is satisfied with the requested safety factor (SF = 4, ID11): 15,750 Nm > $3500 \mathrm{Nm}$ (ID21 > ID8). The same condition also applies (obviously) to the tangential forces $\mathrm{F}_{\mathrm{u}}: 35,000 \mathrm{~N}>7778 \mathrm{~N}$ (ID13 > ID10).

- The axial force $F_{a}$ required for the transmission of the torque is 30,965 N (ID14): it is granted by a hydraulic piston (upon setting the pressure level of the oil, this force is fixed).

- The frictional force $R_{\mu}$, depending on the weight of the rotary table $(40,000 \mathrm{~N}$, ID16) and on the coefficient of friction ( $\sim 0.2$, ID5), is $8138 \mathrm{~N}$. The self-centering capability is verified since the condition $F_{C}>R_{\mu}$ is satisfied (22,326 N $>8138 \mathrm{~N}$, ID15 $>$ ID17).

- The accuracy of the angular positioning is also verified. The friction torque on the bearing surface of the rotating ring, which depends on the frictional force $\mathrm{R}_{\mu}$, on the mean sliding radius (ID18) and on the coefficient of friction (ID5), is $3825 \mathrm{Nm}$; the additional frictional torque for the rotating elements (such as rotary sealings for oil distribution, bearings and gears) is $3000 \mathrm{Nm}$ (ID20). The torque $\mathrm{T}$ that the Hirth connection is able to provide proves to be higher than the total frictional torque $\mathrm{T}_{\mu}: 15,750 \mathrm{Nm}>6825 \mathrm{Nm}(\mathrm{ID} 21>\mathrm{ID} 22)$.

Concerning the stress analysis, it is easy to run this by Equation (3) or (4), with the teeth geometry reported in Figure 14 and considering the full torque capability $\mathrm{T}=15,750 \mathrm{Nm}$. The equations above yield: $\sigma_{\mathrm{b}}=0.23 \mathrm{MPa}$ and $\tau=0.60 \mathrm{MPa}$, which are very far from their admissible thresholds (50 MPa and 18.5 MPa respectively, Table 1).

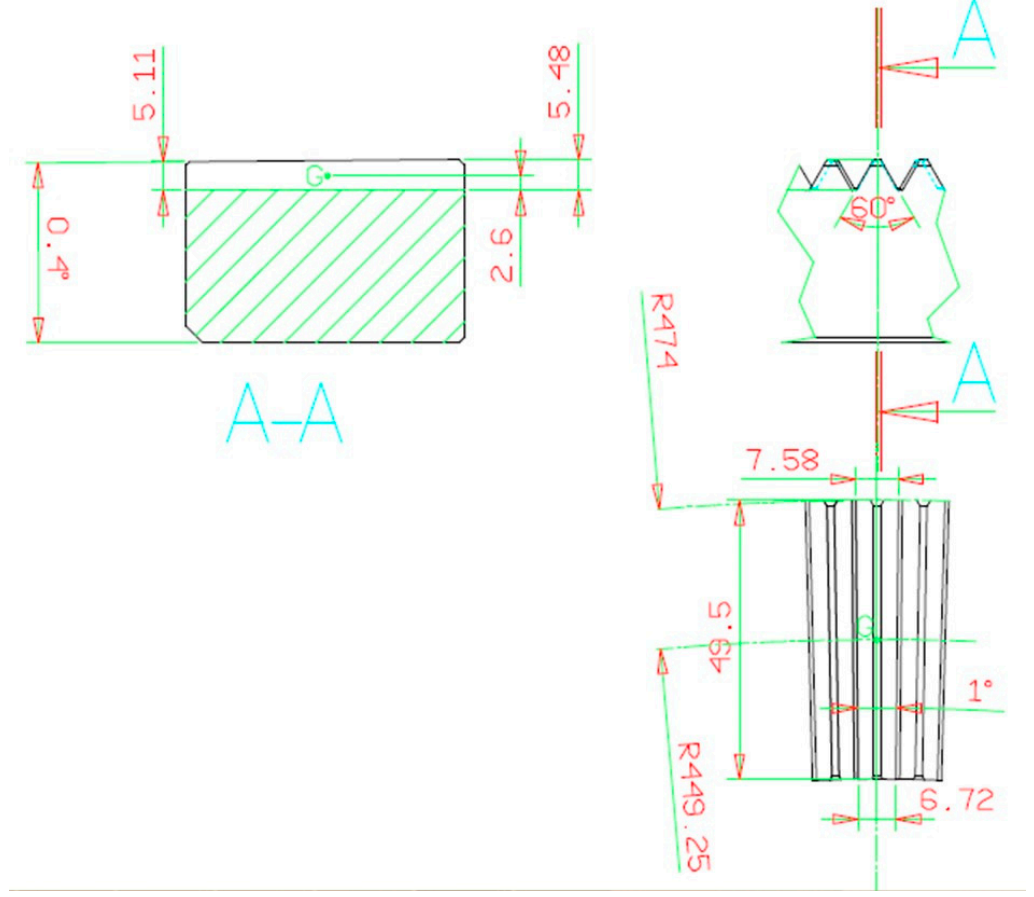

Figure 14. Tooth geometry for the case study.

Finally, the effect of the coefficient of friction is shown. According to [24,25], the coefficient of friction is strongly affected by the presence of the rust, which makes it increase. For this reason, a sensitivity analysis has been performed. The axial force $F_{a}$ has not been modified, provided that the system works with a hydraulic piston set at a fixed pressure level and is able to provide $\mathrm{F}_{\mathrm{a}}=$ $30,965 \mathrm{~N}$ (ID14). $\mathrm{F}_{\mathrm{u}, \mu}$ is therefore recalculated by Equation (8), depending on the actual value of the friction angle $\rho$. The other forces depending on friction are also re-calculated. The results are reported in the chart of Figure 15 and in Table 6, where the double effect of the increase of the coefficient of 
friction is well visible; on one hand, it reduces the capability of the active (self-centering) forces and on the other, it increases the resistance (frictional) forces. In the proposed case study, the detrimental effect of rust is very clear: an increase of the coefficient of friction from its initial value of $\sim 0.2$ (for new surfaces in contact) to a value of 0.4 (or more for the rusted ones) results in the complete loss of the positioning capability of the Hirth connection for the rotary table. This in turn implies the loss of accuracy and precision in the production of the components manufactured by the transfer machine tool. When this situation occurs, the machine tool requires maintenance.

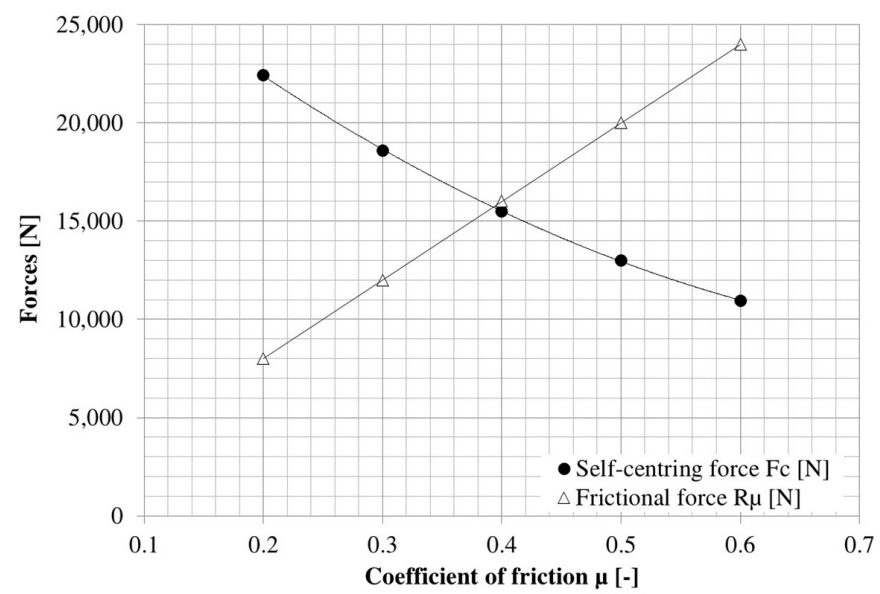

(a)

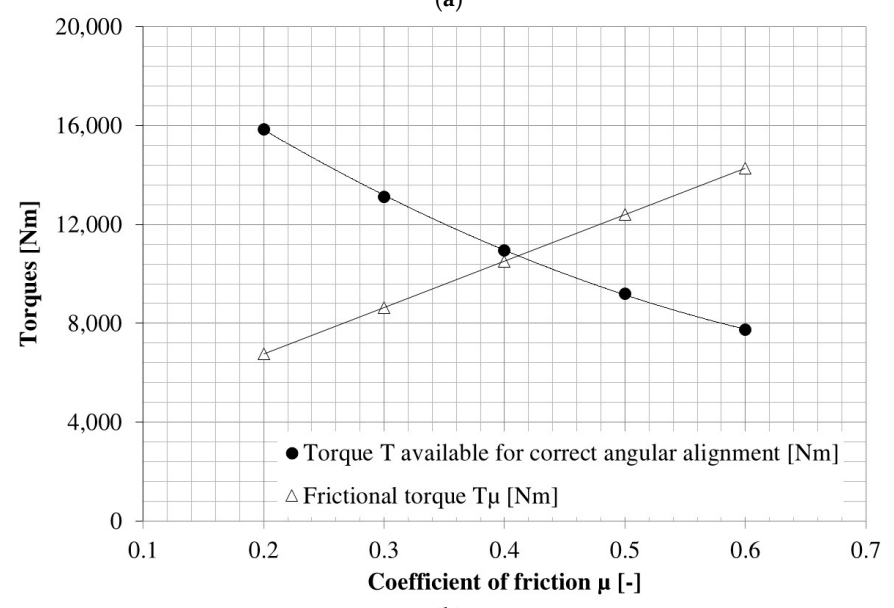

(b)

Figure 15. Sensitivity analysis with the coefficient of friction for (a) forces and (b) torque.

Table 6. Sensitivity analysis for different values of the friction coefficient.

\begin{tabular}{|c|c|c|c|c|c|c|c|c|c|}
\hline \multirow[b]{2}{*}{$\begin{array}{l}\text { Coefficient } \\
\quad \text { of } \\
\text { Friciton } \mu\end{array}$} & \multirow[b]{2}{*}{$\begin{array}{l}\text { Angle of } \\
\text { Friction } \rho \\
\quad\left({ }^{\circ}\right)\end{array}$} & \multirow[b]{2}{*}{$\begin{array}{l}\text { Axial Force } \\
F_{a} \text { from } \\
\text { Hydraulic } \\
\text { Piston }(N)\end{array}$} & \multicolumn{3}{|c|}{ Active Actions Provided by the Hirth } & \multicolumn{2}{|c|}{$\begin{array}{l}\text { Resistance Actions Due to } \\
\text { Friction }\end{array}$} & \multicolumn{2}{|c|}{ Check } \\
\hline & & & $\begin{array}{l}\text { Tangential } \\
\text { Force } F_{u} \\
\text { (N) }\end{array}$ & $\begin{array}{l}\text { Self-Centering } \\
\text { Force } \mathrm{F}_{\mathrm{c}}(\mathrm{N})\end{array}$ & $\begin{array}{l}\text { Torque Available } \\
\text { for Correct } \\
\text { Angular } \\
\text { Alignment (Nm) }\end{array}$ & $\begin{array}{l}\text { Frictional } \\
\text { Force } R_{\mu} \\
\quad(\mathbf{N})\end{array}$ & $\begin{array}{l}\text { Frictional } \\
\text { Torque } T_{\mu} \\
\quad(\mathrm{Nm})\end{array}$ & $\begin{array}{l}\mathbf{F}_{c}> \\
\mathbf{R}_{\mu}\end{array}$ & $\begin{array}{l}\mathrm{T}> \\
\mathrm{T}_{\mu}\end{array}$ \\
\hline 0.200 & 11.3 & & 35,234 & 22,431 & 15,855 & 8000 & 6760 & YES & YES \\
\hline 0.300 & 16.7 & & 29,181 & 18,577 & 13,131 & 12,000 & 8640 & YES & YES \\
\hline 0.400 & 21.8 & 30,965 & 24,366 & 15,512 & 10,965 & 16,000 & 10,520 & NO & YES \\
\hline 0.500 & 26.6 & & 20,445 & 13,016 & 9200 & 20,000 & 12,400 & NO & $\mathrm{NO}$ \\
\hline 0.600 & 31.0 & & 17,190 & 10,944 & 7735 & 24,000 & 14,280 & NO & NO \\
\hline
\end{tabular}

\section{Closed-Form Determination of a Friction Threshold to Ensure Self-Centering}

The outcome of the previous analysis suggests the existence of an upper threshold for friction. For a fixed Hirth geometry, this depends on the applied axial force, $\mathrm{F}_{\mathrm{a}}$, and on the actual overall weight to be moved, W. When friction at the interface is lower than this threshold, the centering force is able 
to warrant full alignment. Conversely, when friction is above this level, due to wear or rust, the axial force is no longer sufficient to allow centering.

Considering Equation (12), the friction threshold can be determined by imposing that the centering force, $F_{c}$, is greater than the frictional force arising from the weight to be moved, $R_{\mu}$. This condition is highlighted in Equation (13), where $\mu$ indicates the frictional coefficient and $\rho$ the corresponding frictional angle:

$$
\mathrm{F}_{\mathrm{c}}=\mathrm{K}_{\mathrm{c}} \cdot \frac{\mathrm{F}_{\mathrm{a}}}{\tan \left(\frac{\pi}{6}+\rho\right)} \geq \mathrm{R}_{\mu}=\mu \cdot \mathrm{W}=\operatorname{tg}(\rho) \cdot \mathrm{W}
$$

Some simple algebraic operations yield the solution in terms of the upper threshold for the frictional coefficient, $\mu_{\mathrm{th}}$ :

$$
\mu_{\text {th. }}=\frac{-\frac{\sqrt{3}}{3}\left(\mathrm{~K}_{\mathrm{c}} \mathrm{F}_{\mathrm{a}}+\mathrm{W}\right)+\sqrt{\frac{1}{3}\left(\mathrm{~K}_{\mathrm{c}} \mathrm{F}_{\mathrm{a}}+\mathrm{W}\right)^{2}+4 \mathrm{WK}_{\mathrm{c}} \mathrm{F}_{\mathrm{a}}}}{2 \mathrm{~W}}
$$

This threshold is plotted in Figure 16, as a function of the applied axial force, for different overall weights to be moved for $K_{C}=0.642(z=360)$. It can be observed that $\mu_{t h}$ exhibits a non-linear increasing trend. The higher the axial force that can be transmitted by the third ring, the higher the frictional threshold, which even tends to unity. Remarkably high values of $\mu_{\text {th. }}$ clearly indicate that the frictional force component can be always easily overcome by the centering force, regardless of the presence of rust or wear. In addition, the higher the weight to be moved, the lower the retrieved threshold. This outcome indicates that, when large masses have to be centered, remarkably high axial forces are required to overcome friction, even for a low frictional coefficient at the interface. Finally, it is interesting to observe that the results in the diagram below are consistent with those of the case study above. In fact, for an axial force of around $31 \mathrm{kN}$ and a weight of $40 \mathrm{kN}$, the friction threshold is 0.395 . This result confirms the unverified condition for centering, as $\mu$ increases up to 0.4 , as shown in Table 6.

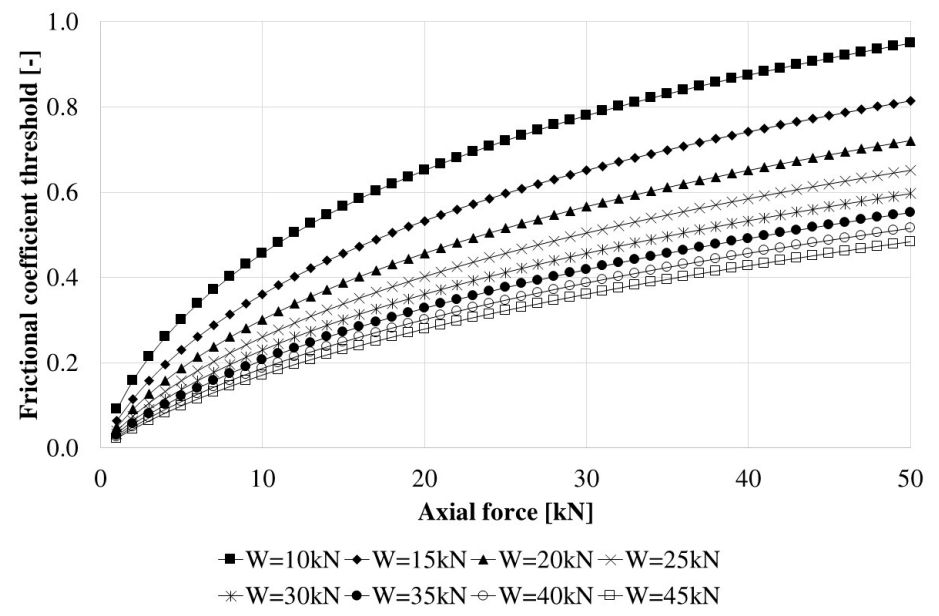

Figure 16. Friction threshold and its dependence on the axial force and the weight to be moved.

\section{Conclusions}

This paper presents a methodology for the precise calculation of the forces generated in Hirth ring connections. The role of friction is taken into account and is demonstrated to be fundamental for the correct calculation of this type of component. Simplified formulae in scientific or technical literature are not sufficiently accurate to describe the performance of Hirth rings in full detail. Starting from a practical example that occurred in a working machine tool that lost the accuracy of its positioning capability, some more advanced design formulae have been proposed. These novel equations have also been experimentally verified. Friction conditions are likely to change during the lifespan of a machine tool, mainly due to wear, rust and corrosion. Therefore, the designer needs to use a reliable design 
method for Hirth connection calculations for long-term life. The developed model, which incorporates the effect of friction, is very important to predict the capability of the connection, and also indicates the related friction thresholds to achieve self-centering and adequate torque transfer.

Author Contributions: Conceptualization, D.C. and N.V.; Data curation, M.D.A., S.F., F.R. and N.V.; Formal analysis, G.O. and N.V.; Investigation, M.D.A., S.F. and N.V.; Methodology, D.C., M.D.A., S.F., G.O. and N.V.; Project administration, D.C. and N.V.; Supervision, D.C., G.O. and N.V.; Validation, N.V.; Writing-original draft, G.O. and N.V.; Writing-revised version, G.O., F.R. and N.V.

Conflicts of Interest: The authors declare no conflict of interest.

\section{Nomenclature}

$\mathrm{A}_{\mathrm{z}} \quad$ Effective tooth flank area $\left(\mathrm{mm}^{2}\right)$

$a^{\prime}, a^{\prime \prime}, h_{G} \quad$ Geometrical features of the Hirth ring and related teeth (from Figure 3)

c Center misalignment between the fixed and the rotating rings ( $\mathrm{mm}$ )

$\mathrm{C}_{\max } \quad$ Maximum center misalignment between the fixed and the rotating rings $(\mathrm{mm})$

D Outer diameter of the teeth $(\mathrm{mm})$

$\mathrm{d} \quad$ Inner diameter of the teeth $(\mathrm{mm})$

$\mathrm{d}_{\mathrm{L}} \quad$ Fixing hole diameter $(\mathrm{mm})$

Factor $\mathrm{c} \quad$ Factor depending on the number of teeth $\mathrm{z}$ (from Table 2)

$\mathrm{F}_{\mathrm{a}} \quad$ Axial force generated by the Hirth coupling $(\mathrm{N}, \mathrm{kN})$

$\mathrm{F}_{\mathrm{c}} \quad$ Self-centering force $(\mathrm{N}, \mathrm{kN})$

$\mathrm{F}_{\mathrm{r}, \mathrm{e}} \quad$ Additional external force in the radial direction (experimental validation test) (N)

FS Safety factor for the total tangential force (-)

$\mathrm{F}_{\mathrm{u}} \quad$ Total tangential force $(\mathrm{N}, \mathrm{kN})$

$\mathrm{F}_{\mathrm{u}, \mu} \quad$ Actual tangential force (including friction) $(\mathrm{N}, \mathrm{kN})$

$\mathrm{F}_{\mathrm{v}-\mathrm{a}} \quad$ Preload $(\mathrm{N}, \mathrm{kN})$, considering a safety factor $v$

h Tooth height $(\mathrm{mm})$

K Reduction factor for the transmitted load (-)

$\mathrm{K}_{\mathrm{C}} \quad$ Coefficient for the self-centering force computation, depending on the number of teeth

$\mathrm{K}_{\mathrm{p}} \quad$ Percentage reduction factor for the tooth pressure (\%)

$\mathrm{n}_{\mathrm{b}} \quad$ Number of bolts in the teeth surface

$\mathrm{p}_{\max } \quad$ Maximum pressure on tooth flank (MPa)

$\mathrm{R} \quad$ Ring diameter ( $\mathrm{mm}$ )

$R_{m} \quad$ Mean radius of the ring $(\mathrm{mm})$

$R_{\mu} \quad$ Frictional resistance force $(\mathrm{N}, \mathrm{kN})$

$\mathrm{r} \quad$ Tooth base radius $(\mathrm{mm})$

$\mathrm{s} \quad$ Crown clearance $(\mathrm{mm})$

$\mathrm{T} \quad$ External torque to be transmitted (Nm, Nmm)

$\mathrm{T}_{\mu} \quad$ Frictional torque (Nm, Nmm)

$\mathrm{W} \quad$ Overall weight to be moved upon self-centering $(\mathrm{N}, \mathrm{kN})$

z Number of teeth (-)

$\gamma \quad$ Angular misalignment between the fixed and the rotating rings $\left(^{\circ}\right)$

$\gamma_{\max } \quad$ Maximum angular misalignment between the fixed and the rotating rings $\left(^{\circ}\right)$

$\eta_{\mathrm{z}} \quad$ Load bearing percentage (-)

$\mu \quad$ Coefficient of friction (-)

$\mu_{\text {th }} \quad$ Coefficient of friction upper threshold to achieve self-centering (-)

$v \quad$ Safety factor for preload (-)

$\theta \quad$ General angular coordinate over the Hirth ring $\left(^{\circ}\right)$

$\rho \quad$ Angle of friction $\left({ }^{\circ}, \mathrm{rad}\right)$

$\sigma_{\mathrm{b}} \quad$ Tooth bending normal stress $(\mathrm{MPa})$

$\sigma_{\mathrm{b} \_ \text {ref }} \quad$ Allowable normal stress $(\mathrm{MPa})$

$\tau$

Shear stress due to the transmitted torque $(\mathrm{MPa})$

$\tau$ _ref Allowable shear stress (MPa) 


\section{References}

1. Hirth, C.A. Shaft Coupling. U.S. Patent 1,660,792, 28 February 1928.

2. Yuan, S.X.; Zhang, Y.Y.; Zhang, Y.C.; Jiang, X.J. Stress distribution and contact status analysis of a bolted rotor with curvic couplings. Proc. I. Mech. Eng. C-J. Mec. 2010, 224, 1815-1829. [CrossRef]

3. Pisani, S.R.; Rencis, J.J. Investigating CURVIC coupling behavior by utilizing two- and three-dimensional boundary and finite element methods. Eng. Anal. Bound. Elem. 2000, 24, 271-275. [CrossRef]

4. Richardson, I.J.; Hyde, T.H.; Becker, A.A.; Taylor, J.W. A validation of the three-dimensional finite element contact method for use with curvic couplings. Proc. Inst. Mech. Eng. G-J. Aerosp. Eng. 2002, 216, 63-275. [CrossRef]

5. Richardson, I.J.; Hyde, T.M.; Becker, A.A.; Taylor, J.W. A three-dimensional finite element investigation of the bolt stresses in an aero-engine curvic coupling under a blade release condition. Proc. Inst. Mech. Eng. G-J. Aerosp. Eng. 2000, 214, 231-245. [CrossRef]

6. Yin, Z.Y.; Hu, B.A.; Wu, J.G.; Xu, Y.L.; Zheng, Q.X. Calculation of axial relaxed/pressed forces of rotors with curvic couplings. Acta Aeronaut. Aeronaut. Sin. 1996, 17, 555-560.

7. Hu, B.A.; Yin, Z.Y.; Xu, Y.L. Determination of axial preloads of rotor with curvic couplings pretightened into two segments. J. Mech. Strength 1999, 21, 274-277.

8. Croccolo, D.; Cavalli, O.; De Agostinis, M.; Fini, S.; Olmi, G.; Robusto, F.; Vincenzi, N. A Methodology for the Lightweight Design of Modern Transfer Machine Tools. Machines 2018, 6, 2. [CrossRef]

9. Cao, H.; Li, D.; Yue, Y. Root Cause Identification of Machining Error Based on Statistical Process Control and Fault Diagnosis of Machine Tools. Machines 2017, 5, 20.

10. Zhang, F.P.; Lu, J.P.; Tang, S.Y.; Sun, H.F.; Jiao, L. Locating error considering dimensional errors modeling for multistation manufacturing system. Chin. J. Mech. Eng. 2010, 23, 765-773. [CrossRef]

11. Du, C.; Zhang, J.; Lu, D.; Zhang, H.; Zhao, W. A parametric modeling method for the pose-dependent dynamics of bi-rotary milling head. Proc. Inst. Mech. Eng. B-J. Eng. Manuf. 2018, 232, 797-815. [CrossRef]

12. Liu, X.; Yuan, Q.; Liu, Y.; Gao, J. Analysis of the stiffness of hirth couplings in rod-fastened rotors based on experimental modal parameter identification. In Proceedings of the ASME Turbine Technical Conference and Exposition, Düsseldorf, Germany, 16-20 June 2014.

13. Du, C.; Zhang, J.; Lu, D.; Zhang, H.; Zhao, W. Coupled Model of Rotary-Tilting Spindle Head for Pose-Dependent Prediction of Dynamics. J. Manuf. Sci. Eng. 2018, 140, 081008. [CrossRef]

14. Matzke, G. Verbindung von Wellen durch Verzahnung. Konstruktion 1951, 3, 211-216.

15. Croccolo, D.; De Agostinis, M.; Fini, S.; Olmi, G. Tribological properties of bolts depending on different screw coatings and lubrications: An experimental study. Tribol. Int. 2017, 107, 199-205. [CrossRef]

16. Croccolo, D.; De Agostinis, M.; Vincenzi, N. A contribution to the selection and calculation of screws in high duty bolted joints. Int. J. Pres. Ves. Pip. 2012, 96, 38-48. [CrossRef]

17. Croccolo, D.; De Agostinis, M.; Vincenzi, N. Influence of tightening procedures and lubrication conditions on titanium screw joints for lightweight applications. Tribol. Int. 2012, 55, 68-76. [CrossRef]

18. Croccolo, D.; De Agostinis, M.; Fini, S.; Olmi, G. An experimental study on the response of a threadlocker, involving different materials, screw dimensions and thread proportioning. Int. J. Adhes. 2018, 83, 116-122. [CrossRef]

19. Croccolo, D.; Vincenzi, N. Tightening tests and friction coefficients definition in the steering shaft of front motorbike suspension. Strain 2011, 47, 337-342. [CrossRef]

20. Niemann, G.; Winter, H.; Hohn, B.R. Maschinenelemente; Springer-Verlag: Berlin, Germany, 2005.

21. Croccolo, D.; De Agostinis, M.; Vincenzi, N. Normalization of the stress concentrations at the rounded edges of a shaft-hub interference fit: Extension to the case of a hollow shaft. J. Strain Anal. Eng. 2012, 47, 131-139. [CrossRef]

22. Croccolo, D.; De Agostinis, M.; Fini, S.; Morri, A.; Olmi, G. Analysis of the influence of fretting on the fatigue life of interference fitted joints. In Proceedings of the ASME International Mechanical Engineering Congress and Exposition, Montreal, QC, Canada, 14-20 November 2014; Volume 2B, p. V02BT02A008. [CrossRef]

23. Jiang, X.J.; Zhang, Y.Y.; Yuan, S.X. Analysis of the contact stresses in curvic couplings of gas turbine in a blade-off event. Strength Mater. 2012, 44, 539-550. [CrossRef] 
24. Croccolo, D.; Cuppini, R.; Vincenzi, N. Friction coefficient definition in compression-fit couplings applying the DOE method. Strain 2008, 44, 170-179. [CrossRef]

25. RR71, Friction in Temporary Works, ISBN 071762613 X, HSE Books. Available online: http:/ / www.hse.gov. $\mathrm{uk} /$ research/rrhtm/rr071.htm (accessed on 19 November 2018).

(․) 1

(C) 2018 by the authors. Licensee MDPI, Basel, Switzerland. This article is an open access article distributed under the terms and conditions of the Creative Commons Attribution (CC BY) license (http:/ / creativecommons.org/licenses/by/4.0/). 